\title{
A review on transition-metal mediated synthesis of quinolines
}

\author{
RASHMI SHARMA, PARTEEK KOUR and ANIL KUMAR* \\ Synthetic Organic Chemistry Lab., Faculty of Sciences, Shri Mata Vaishno Devi University, Katra, \\ Jammu and Kashmir 182 320, India \\ E-mail: anilsharmachemistry@gmail.com
}

MS received 22 January 2018; revised 26 March 2018; accepted 27 March 2018; published online 14 June 2018

\begin{abstract}
Quinoline is one of the important class of heterocyclic compounds which have gained considerable importance because of its high pharmaceutical efficacy and broad range of biological activities such as anticancer, anti-malarial, anti-microbial and anti-asthmatic. As a consequence, the desire for new versatile and efficient route for the synthesis of quinoline scaffolds remains an active and growing area of interest both in academia and industry. However, developments of transition-metal catalyzed synthetic methods have witnessed a dominant position over the past few years for the synthesis of diverse range of complex heterocyclics containing quinoline scaffolds. This review specifically provides an overview of the literature available on the transitionmetal catalyzed synthetic methodologies for the synthesis of polysubstituted quinoline derivatives.
\end{abstract}

Keywords. Heterocycles; quinolines; transition-metal catalyst; synthetic protocols; biological activities.

\section{Introduction}

Over the past few decades, heterocyclic compounds received remarkable attention for variety of reasons and notable amongst them are their bio-activity and their utility as drug molecule. Further, these are also known to occur in numerous functional molecules, natural products, organic materials and pharmaceuticals. Among heterocycles, quinoline scaffolds exhibit wide range of medicinal applications in the treatment of various types of diseases. Quinoline is an N-based six membered fused heterocyclic compound which also received significant attention in recent times ${ }^{1}$ due to its wide range of applications particularly in industrial ${ }^{2}$ and medicinal chemistry. Further, quinoline scaffolds play a significant role in drug discovery as their derivatives have been extensively applied as antimicrobial, ${ }^{3}$ anticancer, ${ }^{4}$ antimalarial, ${ }^{5}$ anti-inflammatory agents. ${ }^{6}$ Quinoline derivatives also find potential application as sensors, ${ }^{7}$ agrochemicals, ${ }^{8}$ luminescent materials ${ }^{9}$ and anti-foaming agents in refineries. ${ }^{10}$ Additionally, they are important constituents of several natural products with inherited medicinal properties. ${ }^{11}$

\section{Quinoline, a versatile biologically significant building block}

\subsection{Biologically active natural products containing quinoline scaffold}

Quinoline heterocycles serve as main constituent of majority of natural products. For example, Transtorine (1) is a quinoline containing natural product extracted from the aerial parts of Ephedra transitoria and has been shown to inhibit bacterial growth of Enterobacter cloacae, Staphylococcus aureus and Pseudomonas aeruginosa. ${ }^{12}$ Cryptolepine (2) an indoloquinoline alkaloid has been applied to cure malaria. ${ }^{13}$ Quinine (3), a well-known anti-malarial drug is an another significant molecule isolated from the bark of cinchona tree. ${ }^{14} \mathrm{On}$ the other hand, Megistoquinone I (6) and Megistoquinone II (7) two potential antibacterial drugs are also belonging to alkaloids, an important class of natural product. ${ }^{15}$ Similarly, Skimmianine (5) is a very useful anti-inflammatory drug. ${ }^{16}$ Importantly, Streptonigrin (8) acting as scission between the DNA strands and lenvatinib (4) being a tyrosine-kinase inhibitor are also used as effective antitumour drugs as per literature records (Figure 1). ${ }^{17}$

\subsection{Antimalarial activity}

Most important application of quinoline based drugs is their efficiency in the treatment of malaria. Chloroquine (9), a 4aminoquinoline derivative has been proved to be an effective medication for treatment of malaria. ${ }^{18}$ Subsequently; new

\footnotetext{
*For correspondence
} 
<smiles>O=C(O)c1cc(=O)c2ccccc2[nH]1</smiles>

1<smiles>CN1C2=c3ccccc3=NC2Cc2ccccc21</smiles>

Cryptolepine

2<smiles>C=CC1CN2CCC1C2[C@H](O)c1ccnc2ccc(OC)cc12</smiles>

3<smiles>COc1cc2nccc(Oc3ccc(NC(=O)NC4CC4)c(Cl)c3)c2cc1C(N)=O</smiles>

4<smiles></smiles>

Figure 1. Quinoline containing natural products.<smiles>CCN(CC)CCCC(C)Nc1ccnc2cc(Cl)ccc12</smiles>

9<smiles>CC(=O)c1cccc2c(C(O)C3CCCCN3)cc(C(F)(F)F)nc12</smiles>

10<smiles>CO/C=C/C1=C(OC)c2c([nH]c(=O)c(OC)cc2=O)C1=O</smiles>

Megistoquinone II

7<smiles>C=CC1CC2CCN1C2[C@H](O)c1ccnc2ccc(OC)cc12</smiles>

11
12<smiles>COc1cc(NC(C)CCCN=C(C)C2CCOC2=O)c2ncccc2c1</smiles>

13<smiles>COc1cc(C)c2c(Oc3cccc(C(F)(F)F)c3)c(OC)cc(NC(C)CCCN)c2n1</smiles>

14<smiles>COc1cc(NC(C)C)c2ncccc2c1</smiles>

15

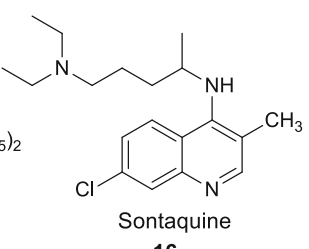

16

Figure 2. Quinoline based antimalarial drugs.

drugs were developed with a hope to overcome the problem of drug resistance. In this context, Mefloquine (10) acting as blood schizonticide was introduced in 1970 and was considered as safe medicine by World Health Organization. ${ }^{19}$ Amodiaquine (11), quinidine (12), aablaquine (13), tafenoquine (14), primaquine (15) and sontaquine (16) are some other frequently used quinoline based antimalarial drugs (Figure 2). ${ }^{18,20}$

\subsection{Anticancer activity}

Quinoline containing molecules have also been shown to possess potent anticancer properties. A few compounds with quinoline ring system displaying potential anti-cancer properties are shown in Figure 3. For example, Camptothecin (17) exhibits the property of topoisomerase inhibition. The topoisomerase inhibition in this case is believed to be due to presence of planar pentacyclic ring structure. Irinotecan (18) is an another significant molecule useful for the treatment of colorectal cancer. ${ }^{21 \mathrm{c}}$ Topotecan (19) has known to apply for small lung cancer therapy by inhibiting the normal functioning of topoisomerase. ${ }^{21 \mathrm{~d}}$ Cabozantinib (20) is known to treat medullary thyroid cancer ${ }^{21 \mathrm{e}}$ and renal cell carcinoma. ${ }^{21 f}$ Exatecan (21) and TAS-103 (22) are some other quinoline based anticancer molecules (Figure 3). ${ }^{22}$

\subsection{Antimicrobial activity}

Microbial infections pose a great danger in present day life and contribute a major factor for the increased mortality rate. Several drugs comprising quinoline moiety have been explored and developed as anti-microbial drugs during 

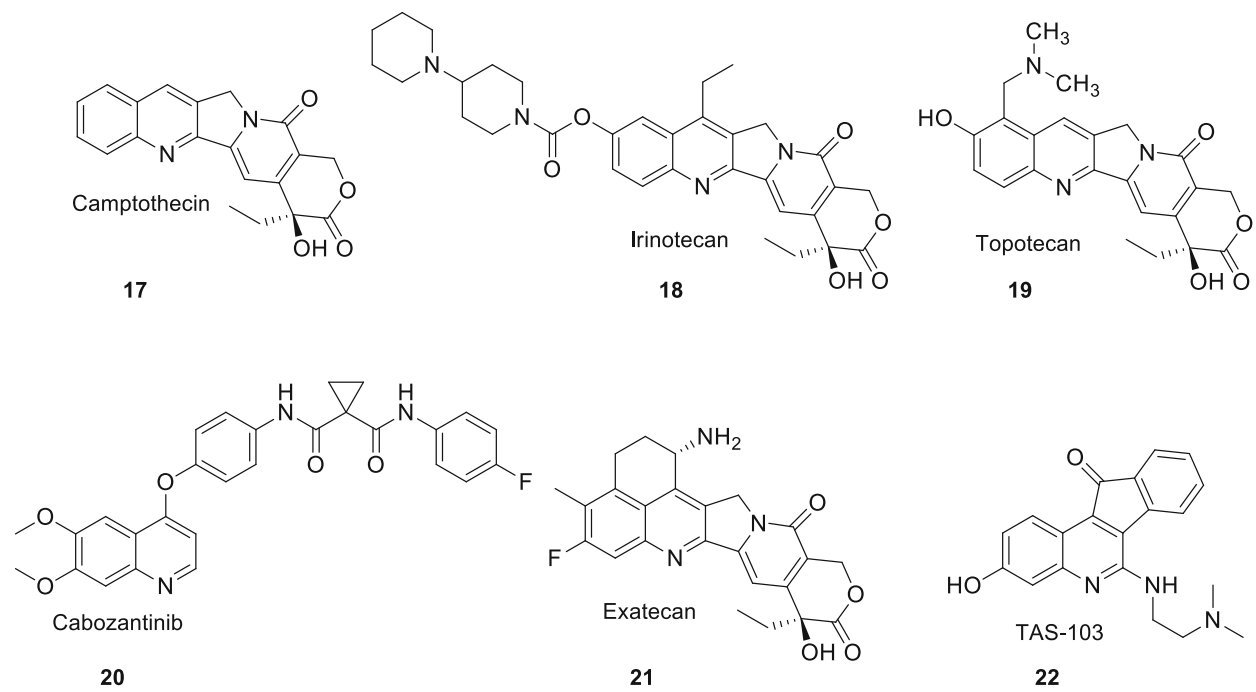

Figure 3. Quinoline based anticancer drugs.<smiles>O=C(O)c1cn(C2CC2)c2cc(N3CCNCC3)c(F)cc2c1=O</smiles>

23<smiles>CC1CN(c2c(F)cc3c(=O)c(C(=O)O)cn(C4CC4)c3c2OCC2CC2)CCN1</smiles>

26<smiles>CCn1cc(C(=O)O)c(=O)c2cc(F)c(N3CCNCC3)cc21</smiles>

29<smiles>CC1CN(c2c(F)c(N)c3c(=O)c(C(=O)O)cn(C4CC4)c3c2F)CC(C)N1</smiles>

24<smiles>C[C@@H]1COc2c(N3CCN(C)CC3)c(F)cc3c(=O)c(C(=O)O)cn1c23</smiles>

25<smiles></smiles>

27<smiles>Cc1c(F)c(N2CCNC(C)C2)cc2c1c(=O)c(C(=O)O)cn2C1CC1</smiles>

28<smiles>CC1COc2c(N3CCN(C)CC3)c(F)cc3c(=O)c(C(=O)O)cn1c23</smiles>

30<smiles>CCn1cc(C(=O)O)c(=O)c2cc(F)c(N3CCN(C)CC3)cc21</smiles>

31

Figure 4. Quinoline containing antimicrobial drugs.

past decades. For example, Ciprofloxacin (23) and Norfloxacin (29), fluoroquinoline derivatives were developed as an effective antimicrobial drug and used for treatment of joint, respiratory and urinary tract infections. ${ }^{23 a}$ It is often prescribed for polymicrobial infections involving clostridia. Sparfloxacin (24) is another commonly available drug used to treat community acquired acute sinusitis, chronic bronchitis and pneumonia. ${ }^{23 \mathrm{~b}}$ However, other new drugs like levofloxacin (25), gatifloxacin (26) and moxifloxacin (27) also display excellent therapeutic activity for treatment of community acquired diseases. ${ }^{24}$ Grepafloxacin (28), ofloxacin (30) and pefloxacin (31) are some other quinoline based antimicrobial drugs ${ }^{25}$ (Figure 4).

\section{Traditional routes for the synthesis of quinoline scaffolds}

Due to widespread applications of quinoline, several classical approaches have been devised and well documented in the literature. The important amongst them are (i) Knorr (ii) Friedlander (iii) Skraup (iv) Combes (v) Doebner-von Miller (vi) Pfitzinger and (vii) ConradLimpach synthesis. These traditional methods have been utilized for long time to generate quinoline scaffolds through the reaction schemes as outlined in Figure 5. Although all these reported literature methods were 

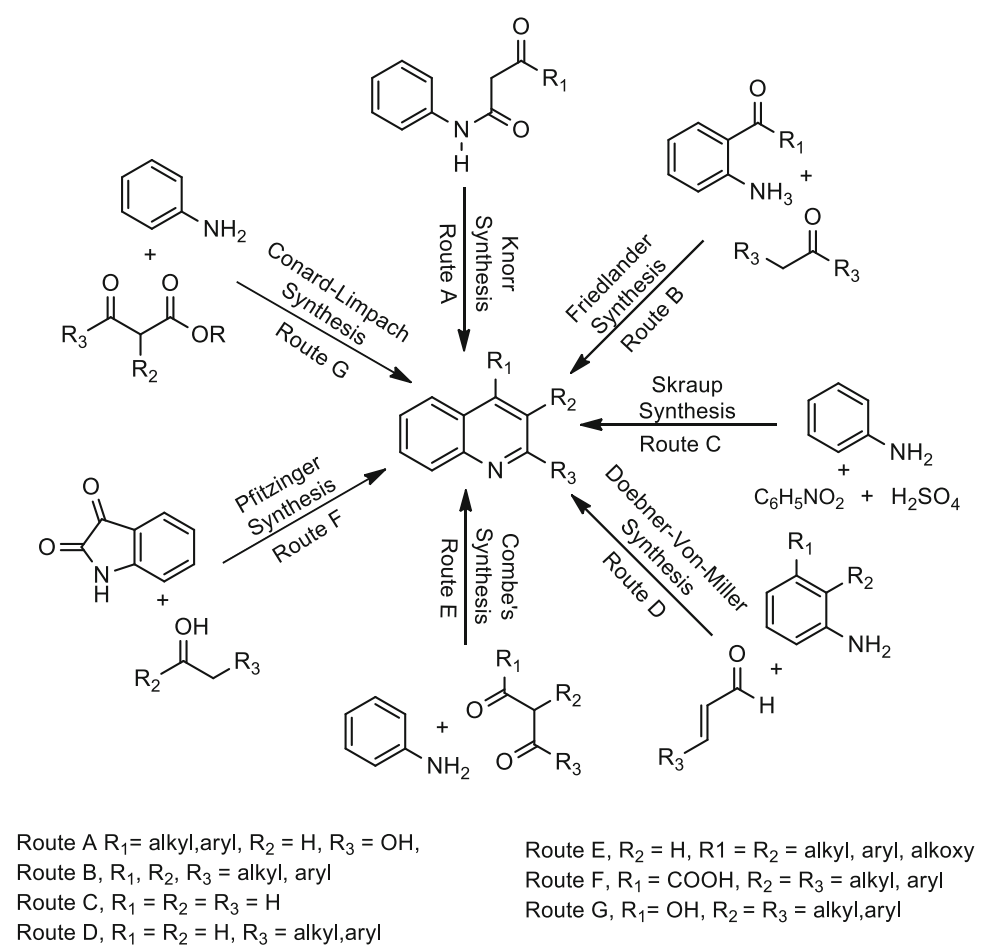

Route $E, R_{2}=H, R 1=R_{2}=$ alkyl, aryl, alkoxy Route $F, R_{1}=\mathrm{COOH}, \mathrm{R}_{2}=\mathrm{R}_{3}=$ alkyl, aryl Route $\mathrm{G}, \mathrm{R}_{1}=\mathrm{OH}, \mathrm{R}_{2}=\mathrm{R}_{3}=$ alkyl,aryl

Figure 5. Traditional routes for the synthesis of quinolines.

highly appreciable as they provided infinite access to libraries of lead candidates but most approaches are plagued with disadvantages such as use of acid or hazardous catalysts, extreme reaction conditions and tedious work up procedures. Thus, over the years researchers tried to circumvent these problems and in this context, extensive efforts have been made by them by innovating new and efficient routes for organic transformations to access diversified quinoline scaffolds. As a consequence, development of new routes either through modification of the known methods or by employing transition-metal supported coupling reaction, or via multi-component approaches are amongst the prominent ones finding mention in the literature.

On the other hand, transition-metal catalyzed synthetic methods have witnessed a dominant position in the past decades in organic and medicinal chemistry especially for the synthesis of complex quinoline based heterocycles. Transition metal and their complexes are very attractive due to their appealing catalytic ability to generate lead drug candidates. They have created an edge over the traditional synthetic route as they aid in construction of complex compound libraries from readily available starting materials. These metals and their complexes can act as an alternative to more costly and hazardous catalysts for the preparation of quinoline based therapeutic molecules from the easily available materials. ${ }^{26}$
Based on above mentioned therapeutic potential of quinoline scaffolds, many reviews on synthesis ${ }^{27}$ and biological activities ${ }^{20,22,23,25,28}$ of quinoline based molecules have been documented in the literature during the past few years. Further, considerable efforts have been devoted for the preparation of these scaffolds during past few years using readily available transition metal salts and their complexes. However, till date there is no review reported which exclusively deals with transition metal catalyzed routes for the synthesis of substituted quinoline derivatives. In view of our interest in quinoline heterocycles ${ }^{29}$ herein we aim to focus particularly on the comprehensive literature compilation of transition-metal based synthetic strategies devoted for the synthesis of quinoline scaffolds.

\section{Various approaches for the synthesis of quinolines and their derivatives using transition-metal catalysis}

A convenient and efficient protocol was developed by Zhong et al., for the synthesis of series of 2,4disubstituted quinolines (34) in moderate to good yields via iron-catalyzed reaction of arylnitrones (32) with geminal-substituted vinyl acetates (33) (Scheme 1). Based on the initial investigation it was proposed that the 


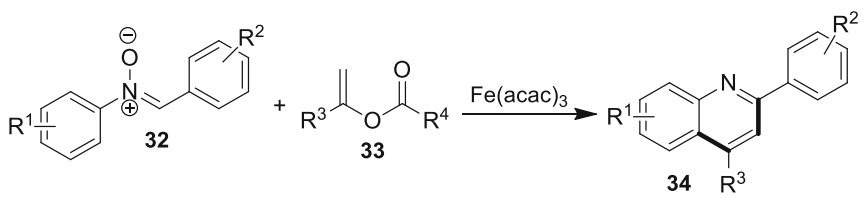

Scheme 1. Iron-catalyzed synthesis of 2, 4-disubstituted quinolines.

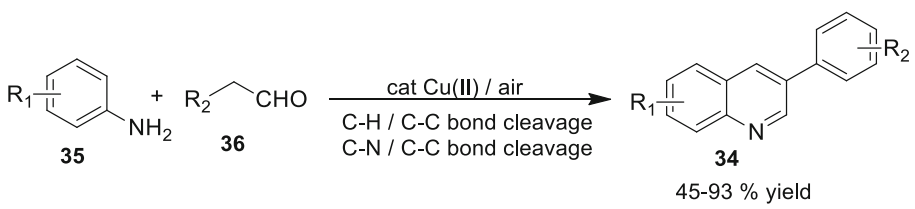

Scheme 2. Cu catalyzed synthesis of polysubstituted quinolines under aerobic condition.

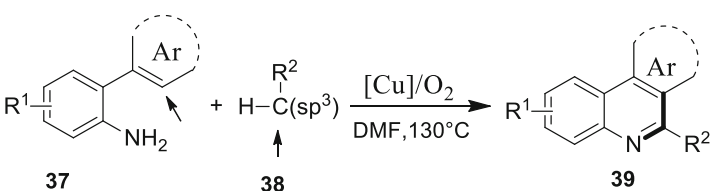

Scheme 3. Tandem oxidative cyclization route to substituted quinolines.

reaction proceeds through intermolecular [4+2] cyclization reaction directed by $\mathrm{C}-\mathrm{H}$ activation. Further the developed protocol showed good functional group tolerance. $^{30}$

Yan et al., has demonstrated copper-catalyzed one pot, simple, and efficient strategy for the synthesis of substituted quinolines (34) (Scheme 2). ${ }^{31}$ The method involves the reaction of anilines (35) and aldehydes (36) and proceeded initially via $\mathrm{C}-\mathrm{H}$ functionalization followed by the construction of C-N/C-C bond, and cleavage of $\mathrm{C}-\mathrm{C}$ bond. In this study, molecular oxygen was employed as an oxidant which makes this process a convenient and economical approach.

A modified one-pot $\mathrm{Cu}$-catalyzed tandem aerobic oxidative cyclization procedure has been disclosed by Pang et al., which allows the preparation of polysubstituted quinolines (39) from 2-vinylanilines/2-arylanilines (37) and 2-methylquinolines via $\mathrm{C}\left(\mathrm{sp}^{3}\right)-\mathrm{H} / \mathrm{C}\left(\mathrm{sp}^{2}\right)-\mathrm{H}$ (38) bond functionalization by using dioxygen as oxidant (Scheme 3). Further, the protocol was successfully extended with 2-methyl-1,2,3,4-tetrahydroquinoline to deliver desired products in moderate yields. ${ }^{32}$

Mondal et al., has disclosed an unprecedented solvent free, $\mathrm{CuBr}-\mathrm{ZnI}_{2}$ combo-catalyzed $\mathrm{Cu}^{1}-\mathrm{Cu}^{\mathrm{III}}$ switching

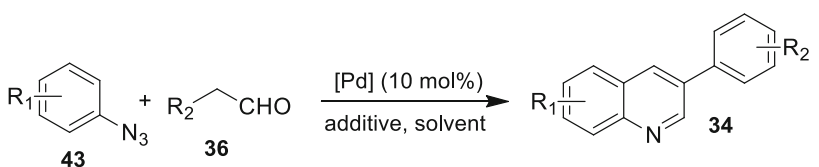

Scheme 5. Palladium catalyzed synthesis of 3-phenylquinolines.

strategy to generate substituted quinolines through sp2 $\mathrm{C}-\mathrm{H}$ activation of highly electron-rich arenes. In this protocol, substituted aniline (35), aldehydes (41), and terminal alkynes (40) were rapidly coupled to generate the desired quinoline (42) framework through cyclization of the $\mathrm{c} \equiv \mathrm{c}$ bond (Scheme 4$)$. Further, the developed methodology was efficiently utilized for the synthesis of valuable 4-substituted, 2, 4-disubstituted, and sugar-based chiral quinolines in good yields. ${ }^{33}$

A novel, one-pot aerobic strategy with a broad substrate scope was introduced by Luo et al., to deliver 3-phenylquinolines (34) from azides (43) and aldehydes (36) using $10 \% \mathrm{PdCl}_{2}$ in DMSO via $\mathrm{C}$ - $\mathrm{H}$ functionalisation and $\mathrm{C}-\mathrm{C}$ bond cleavage followed by formation of one $\mathrm{C}-\mathrm{N}$ and two $\mathrm{C}-\mathrm{C}$ bonds (Scheme 5). ${ }^{34}$

One-pot synthesis of quinolines was established by Nikolaev et al., via cross-coupling of unprotected orthobromoanilines (44) with a wide range of cyclopropanols (45) (Scheme 6). They further demonstrated that the reaction proceeded in a single operation via intramolecular condensation and palladium-catalyzed oxidation sequence to afford the desired product (46). ${ }^{35}$

A Palladium-catalyzed one-pot, controlled and efficient protocol leading to the construction of quinoline

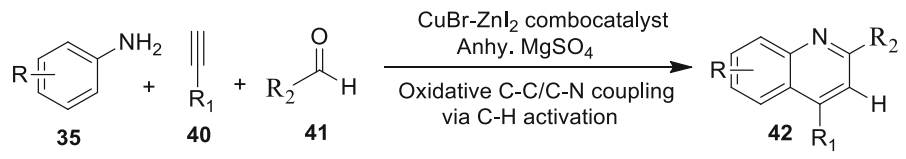

Scheme 4. $\mathrm{CuBr}-\mathrm{ZnI}_{2}$ combo-catalyzed synthesis of quinolines via $\mathrm{C}-\mathrm{H}$ ctivation. 


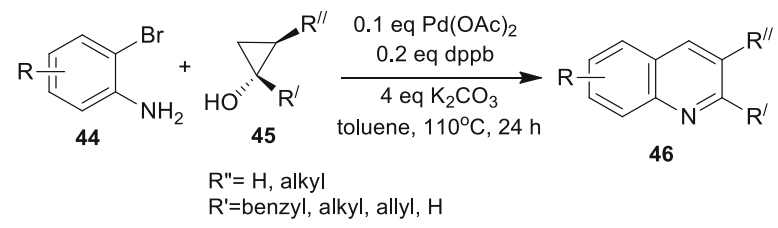

Scheme 6. Construction of quinolines via cross coupling of $o$-bromoanilines and cyclopropanols.

derivatives (50) was reported by Selvakumar et al. The method proceeded via Heck reaction followed by cyclization of (het) aryl-substituted Morita-BaylisHillman (MBH) adducts (47) (Scheme 7) with 2iodoaniline (48). In this reaction, the $\mathrm{MBH}$ adducts initially convert into $\alpha$-benzyl $\beta$-keto ester derivatives (49) which finally undergoes cyclization to deliver desired quinolines in good yield. ${ }^{36}$

A domino approach has been developed by Gao et al. (Scheme 8). ${ }^{37}$ In this protocol benzimidoyl chlorides (51) undergoes reaction with 1,6-enynes (52) to form alkynyl amidine (53) which subsequently afford the desired quinolines motifs $(\mathbf{5 4})$. The reaction proceeded through palladium catalyzed Sonogashira coupling to give good yield under mild reaction conditions utilizing easily accessible raw material.

Liu et al. has developed an effective, regioselective and robust route to afford series of 4-halo-2aminoquinolines in moderate to excellent yields (4794\%) (57) through oxidative cyclization of easily accessible 2-ethynylanilines (55) with isocyanides (56) by Palladium (Scheme 9). Further, this strategy have been successfully used to generate diverse $6 \mathrm{H}$-Indolo [2, 3-b] quinolines. $^{38}$

Straightforward benzylation approach has been developed by Tan $e$ al., to access $\beta$-benzylated quinoline (59)

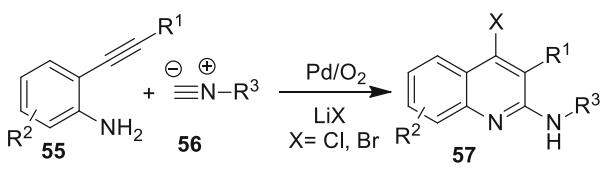

Scheme 9. Regioselective synthesis of aminoquinolines through oxidative cyclization.

from 1,2,3,4-tetrahydroquinolines (58) and aryl aldehydes (41). This cross-coupling strategy employed the use of readily available $\left[\mathrm{RuCl}_{2} \text { (p-cymene) }\right]_{2}$ as a catalyst and $\mathrm{O}_{2}$ as a green oxidant (Scheme 10). In this protocol it was proposed that reaction proceeded in a mono-dehydrogenation-triggered benzylation mode. ${ }^{39}$

An improved, economical and highly-efficient palladium-catalyzed strategy for the construction of 3aryl-2-aminoquinolines (62) from gem-dibromovinylanilines $(\mathbf{6 0})$, tert-butyl isocyanide and arylboronic acids (61) was reported by Huet al. (Scheme 11). This strategy initially involves insertion of isocyanide and then gemdibromovinylanilines which finally undergoes reaction with arylboronic acids via Suzuki coupling to produce the suitably substituted quinoline. ${ }^{40}$

$\mathrm{Fe}(\mathrm{acac})_{3} / \mathrm{TBAOH}$ catalyzed multi-component approach was introduced by Patil et al., for the synthesis of aminoindolizines and quinoline derivatives (64) via coupling-cycloisomerization reaction of amines (35), aldehydes (63) and terminal alkynes (40) (Scheme 12). The advantage of the methodology is its applicability to generate a diverse range of heterocyclic compounds. ${ }^{41}$

A solvent-free, one-pot, and environment-friendly synthesis of 2,4-disubstituted quinolines (67) was achieved by Baltork et al., by the reaction of differently substituted 2-aminoaryl ketones (65) with range of arylacetylenes (66) utilizing $\mathrm{K}_{5} \mathrm{CoW}_{12} \mathrm{O}_{40} \cdot 3 \mathrm{H}_{2} \mathrm{O}$ as catalyst

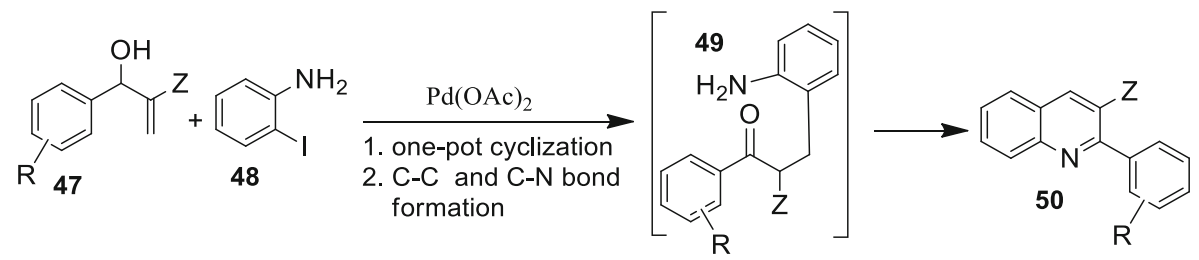

Scheme 7. $\mathrm{Pd}(\mathrm{OAc})_{2}$-catalyzed synthesis of 2, 3-disubstituted quinolines from Morita-Baylis-Hillman (MBH) adducts.

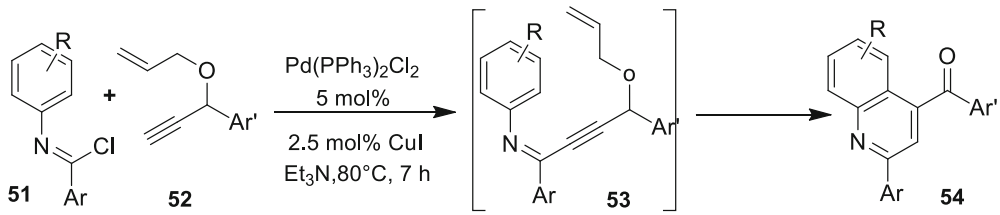

Scheme 8. Domino approach to quinoline derivatives through Sonogashira coupling. 


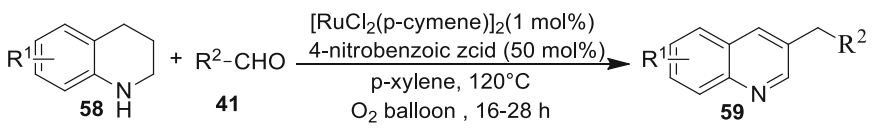

Scheme 10. Ruthenium catalyzed synthesis of $\beta$-benzylated quinolines.

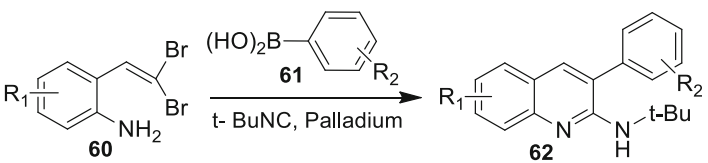

Scheme 11. Cascade synthesis of 3-aryl-2-aminoquinolines using Palladium catalyst.

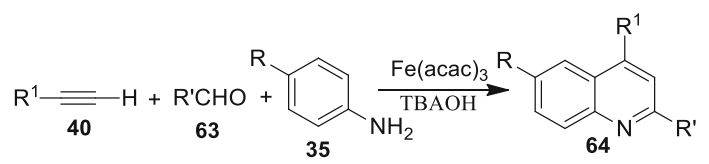

Scheme 12. Multi-component coupling-cycloisomerization route to quinoline derivatives.

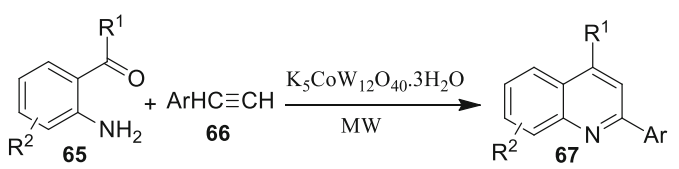

Scheme 13. Microwave promoted synthesis of 2,4-disubstituted quinolines.

under microwave irradiation. The important features of this protocol are the use of microwave technology, environmentally benign catalytic system, reusability of catalysts, and no use of solvent (Scheme 13). ${ }^{42}$

Huma et al., has developed a $\mathrm{CuCl}$ catalyzed one-pot approach by the reaction of substituted aryl aldehyde (41), aryl amine (35) and a terminal alkyne (40) to generate 2,4-disubstituted quinolines (42) in good yield (Scheme 14). ${ }^{43}$

A copper-catalyzed, cost effective, efficient and convenient route has been established by Huang et al. for the preparation of varied quinoline-2-carboxylates (69) under ambient condition. It was proposed that the reaction occurred through intermolecular addition of alkynes (40) into imines (68) followed by intramolecular ring closure to give the desired products. (Scheme

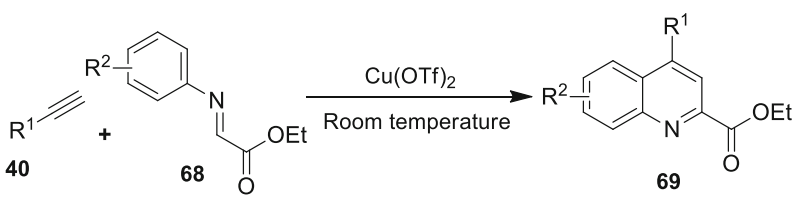

$\mathrm{R}^{1}=\mathrm{Ar}$, alkyl $\quad \mathrm{R}^{2}=\mathrm{Me}, \mathrm{OMe}, \mathrm{OBn}$

Scheme 15. Tandem approach for the synthesis of quinoline-2-carboxylates.

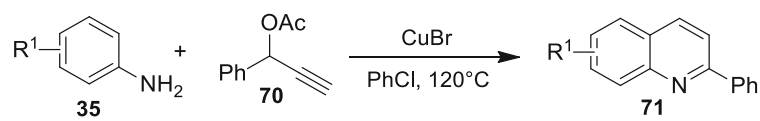

Scheme 16. Copper catalyzed synthesis of quinolines via $\mathrm{C}-\mathrm{N}$ and $\mathrm{C}-\mathrm{C}$ bonds formation.

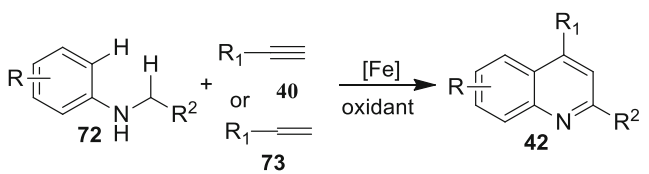

Scheme 17. Iron mediated oxidative coupling route for the generation of quinoline derivatives.

15). Further, the method is compatible with range of functional groups to give the products in good yield. ${ }^{44}$

Zeing and co-workers demonstrated a novel route for generating quinolines (71) in good yields under aerobic conditions. In this copper-catalyzed cascade synthetic route, anilines (35) and terminal acetylene esters (70) undergo transformation via formation of $\mathrm{C}-\mathrm{N}$ and $\mathrm{C}-\mathrm{C}$ bonds. (Scheme 16). ${ }^{45}$

Liu et al., has demonstrated a simple and efficient $\mathrm{Fe}$-catalyzed oxidative coupling route for the synthesis of substituted quinoline (42). In this protocol $\mathrm{N}$-alkyl anilines (72) undergoes reaction with alkynes (40) or alkenes (73). The cheap, easily available and environmentally benign iron was effectively used in presence of oxidant under mild conditions (Scheme 17). ${ }^{46}$

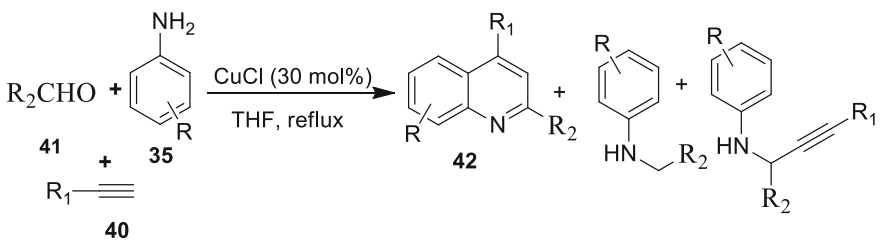

Scheme 14. $\mathrm{CuCl}$ catalyzed one-pot preparation of 2,4-disubstituted quinolines. 


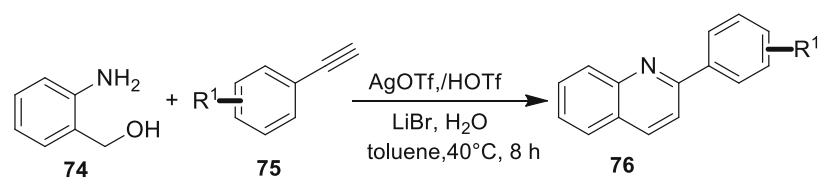

Scheme 18. AgOTf-catalyzed synthesis of 2-substituted quinolines.

AgOTf-catalyzed, simple, cost-effective and atomefficient pathway has been established by $\mathrm{Xu}$ et al. (Scheme 18). In this protocol construction of 2-substituted quinolines (76) was successfully done by the reaction of 2-aminobenzyl alcohol (74) and alkyne (75)/ketone. Similarly 2-aminophenethyl alcohol and aldehyde can also undergo reaction under this protocol to generate the desired products in moderate to excellent yield. Further the method is efficient with both electron-withdrawing and electron-releasing groups on aldehydes, ketones and alkynes. ${ }^{47}$

An improved methodology for the preparation of quinolines derivatives (79) and quinolones (80) was reported by Maizuru et al., in which readily available benzoxazinones (77) react with alkynes (78) to afford substituted quinolines or quinolones via nickelcatalyzed cycloaddition (Scheme 19). ${ }^{48}$

Nickel-catalyzed simple, convenient and efficient method leading to the formation of disubstituted quinolines (42) was demonstrated by Korivi et al. (Scheme 20). In this study, 2-iodoanilines (81) undergoes cyclization with alkynyl aryl ketones (82) to deliver desired products in good yields. The protocol tolerates a broad range of functional group by utilizing inexpensive catalyst. ${ }^{49}$

A Zinc(II) triflate catalyzed solvent-free, atomeconomic, multi-component approach was demonstrated by Sarode et al., for the preparation of substituted quinolines (42) (Scheme 21) by the reaction of amines (35), alkynes (40) and aldehydes (41) in an ambient atmosphere. Further, the protocol works under mild reaction conditions and avoids the use of toxic solvents and expensive metals. ${ }^{50}$

Zheng et al., has developed a new regioselective approach to construct 2, 3-disubstituted quinolines (85)

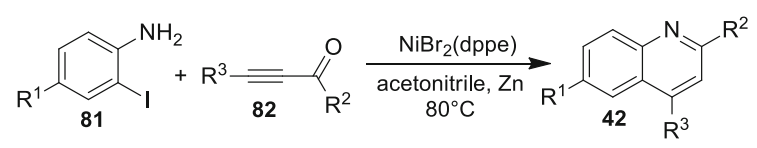

Scheme 20. Nickel-catalyzed preparation of substituted quinolines.

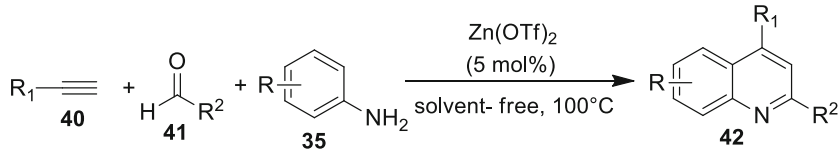

Scheme 21. Zn (OTf $)_{2}$ catalyzed preparation of 2,4-disubstituted quinolines.

via $\mathrm{Pd}$-catalyzed intermolecular oxidative cyclization of $o$-vinylanilines (83) and alkynes (84) assisted with $\mathrm{Cu}$ and $\mathrm{O}_{2}$ (Scheme 22). This transformation was supposed to proceed through sequential intermolecular amination of alkyne, olefin insertion, followed by aerobic cleavage of C-C bond. ${ }^{51}$

A Rh (III) catalyzed simple, regioselective and atomeconomic approach has been developed by Song et al. for the synthesis of quinolines (87) using $\mathrm{Cu}(\mathrm{OAc})_{2}$ as oxidant (Scheme 23). The reaction involves oxidative annulation of pyridine (86) with two alkyne molecules to give excellent yield. The reaction worked well with variety of pyridines to generate diverse quinolines. ${ }^{52}$

A ruthenium-catalyzed one-pot domino protocol based on [3+3] annulation of anilines (35) with varied allyl alcohols (88) was introduced by Kumar et al., for the synthesis of quinolines (89) (Scheme 24). In this reaction, a transient directing group strategy utilizing ruthenium-catalyzed $\mathrm{C}-\mathrm{H}$ bond activation was used to deliver the required product. ${ }^{53}$

A range of substituted quinolines (46) were synthesized using the palladium-catalyzed oxidative cyclization of aryl allyl alcohols (90) and anilines (35) by $\mathrm{Xu}$ and colleagues (Scheme 25). This process works well without the use of acid, base or any additive to deliver satisfactorily yield of products. Additionally, the demonstrated method offers broad substrate scope and

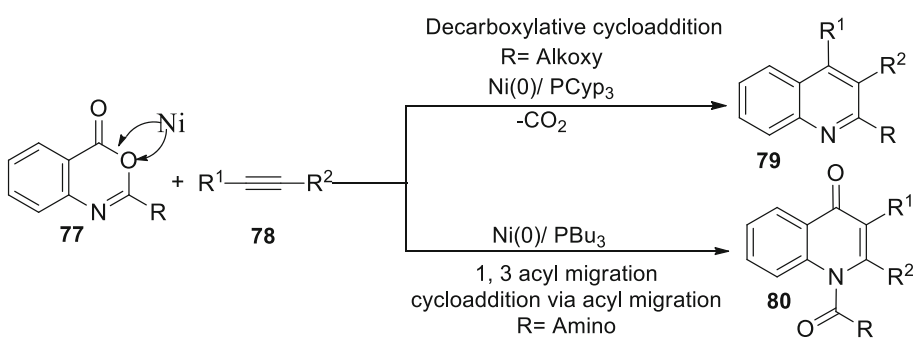

Scheme 19. Nickel-catalyzed formation of quinolines and quinolones. 


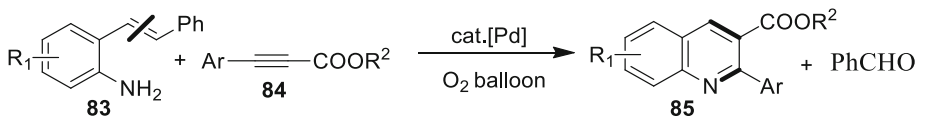

Scheme 22. Aerobic annulation of $o$-vinylanilines and alkynes to synthesize 2,3-disubstituted quinolines.

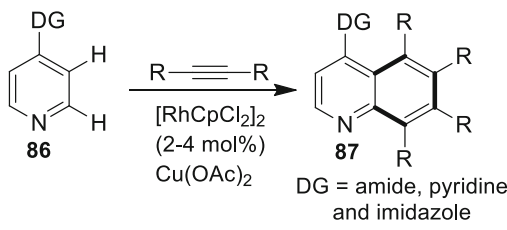

Scheme 23. Cascade synthesis of quinolines using $\mathrm{Rh}$ (III) catalyst and $\mathrm{Cu}(\mathrm{OAc})_{2}$ oxidant.

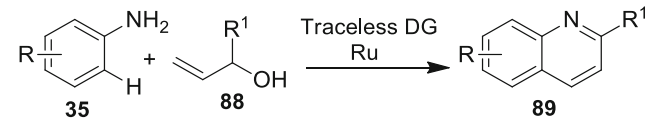

Scheme 24. Ruthenium-catalyzed domino synthesis of quinolines.

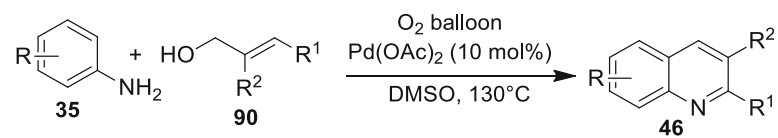

Scheme 25. Palladium-catalyzed synthesis of quinoline derivatives.

high tolerance of electron-withdrawing group such as fluorine, trifluoromethyl and nitryl. ${ }^{54}$

Mastalir and his colleagues presented a new approach for the regioselective synthesis of quinoline derivatives (93) using combinations of 2-aminobenzyl alcohols (91) and secondary alcohols (92) in presence of hydride Mn (I) PNP pincer complex as catalyst (Scheme 26). It was observed that the reaction proceeded through sequence of dehydrogenation and condensation steps in excellent yields. Further, the disclosed methodology was ecofriendly, atom-efficient, sustainable and showed wide range of functional group tolrance. ${ }^{55}$

Wang and co-workers introduced a novel approach to generate range of substituted quinolines based on acceptor less dehydrogenative cyclization in water. In this strategy, a water soluble $\left[\mathrm{Cp}^{*} \operatorname{Ir}\left(6,6^{\prime}-(\mathrm{OH})_{2}\right.\right.$ bpy $\left.)\left(\mathrm{H}_{2} \mathrm{O}\right)\right]$ $[\mathrm{OTf}]_{2}$ was utilized for the cyclization of $o$-aminobenzyl alcohols (94) with ketones (95) yielding quinolines (46) via acceptor less dehydrogenative cyclization (Scheme 27). Further, no side-product was observed by the selfcondensation of $o$-aminobenzaldehyde akin to that of traditional Friedlander protocol. ${ }^{56}$

Chen et al., has introduced a $\left[\mathrm{Ir} \mathrm{Cp} * \mathrm{Cl}_{2}\right]_{2} / \mathrm{KOH}$ catalyzed synthesis of quinolines (98) (Scheme 28) in moderate to good yields. This tandem approach involves the isomerisation/cyclization reaction of allylic alcohols (97) with 2-aminobenzyl alcohol (96). The reaction was successful with both the primary and secondary allylic alcohols to afford differently substituted quinolines. ${ }^{57}$

A one-pot, simple, facile synthesis of quinolines (99) using bifunctional Ru-grafted hydrotalcite catalyst via aerobic oxidation condition and aldol reaction was

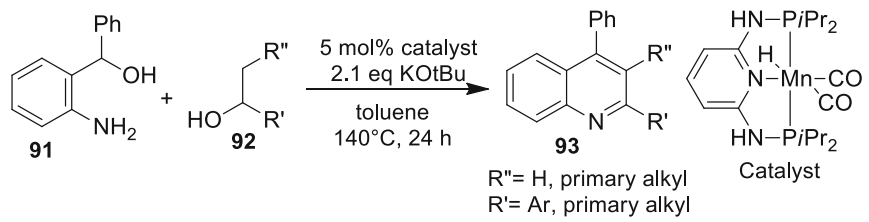

Scheme 26. Synthesis of quinoline derivatives using Mn (I) PNP pincer complex catalyst.
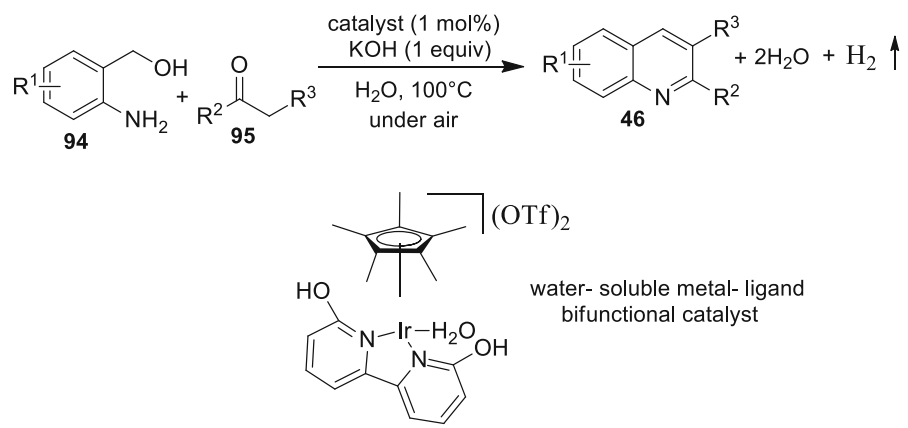

Scheme 27. Iridium-bifunctional catalyzed synthesis of quinolines via acceptorless dehydrogenative cyclization. 


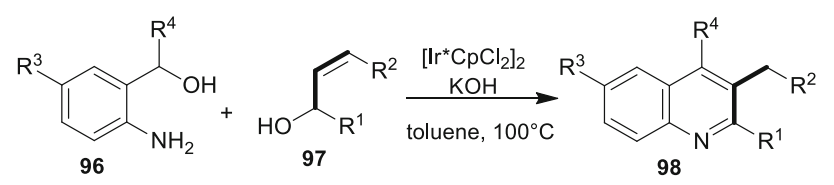

Scheme 28. $\left[\mathrm{Ir} \mathrm{Cp}^{*} \mathrm{Cl}_{2}\right]_{2} / \mathrm{KOH}$ catalyzed formation of quinoline derivatives.

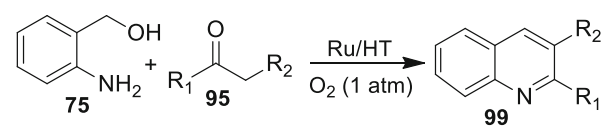

Scheme 29. Ru-grafted hydrotalcite catalyzed synthesis of quinolines.

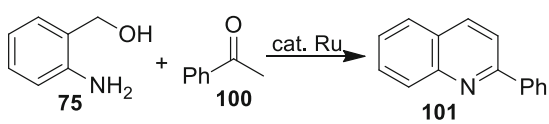

Scheme 30. Modified Friedlander protocol for the synthesis of quinoline derivatives.

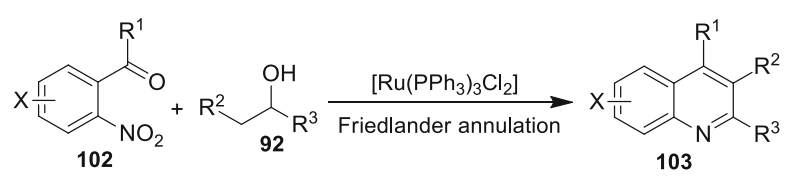

Scheme 31. Rutenium catalyzed cascade synthesis of quinolines.

developed by Motukura and co-workers. In this reaction, 2-aminobenzyl alcohol (75) was made to react with range of carbonyl compounds (95) to deliver varied quinoline (Scheme 29). Further, the method was successfully extended with $\alpha, \beta$-unsaturated nitriles, ketones and aldehydes to generate diverse quinoline derivatives. ${ }^{58}$

A ruthenium-catalyzed modified Friedlander synthesis of quinoline via oxidative cyclization of 2aminobenzyl alcohol (75) with different ketones (100) was introduced by Cho et al. (Scheme 30). Under this protocol the reaction was carried out in dioxane at $80^{\circ} \mathrm{C}$ using catalytic amount of ruthenium and $\mathrm{KOH}$ to afford high yield of the desired quinolines (101). ${ }^{59}$

A $\left[\mathrm{Ru}\left(\mathrm{PPh}_{3}\right)_{3} \mathrm{Cl}_{2}\right]$-catalyzed new and an efficient strategy for the synthesis of quinoline (103) based on modified Friedlander annulations of 2-nitrobenzaldehydes (102) with alcohols (92) was developed by Li et

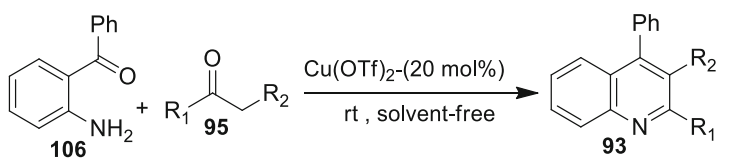

Scheme 33. $\mathrm{Cu}(\mathrm{OTf})_{2}$ modified Friedlander approach to quinolines.

al. (Scheme 31). Both these substrates which are hitherto un-reactive were initially converted to the reactive moieties via a hydrogen transfer reaction. The catalyst serves the dual role of catalyzing both the transfer hydrogen reaction and Friedlander annulation. ${ }^{60}$

An inexpensive, sustainable and air-stable, combo $\mathrm{CuSO}_{4}$-D-glucose catalyst system was developed by Anand and colleagues for the synthesis of functionalized quinoline via modified Friedlander approach (Scheme 32). The developed route was based on the domino multi-component approach which directly leads to the construction of substituted quinolines (105) from 2-bromoaromatic aldehydes/ketones (104) using $\mathrm{H}_{2} \mathrm{O}-\mathrm{EtOH}$ as green solvent. Further, the reaction was successfully extended for gram scale synthesis of quinoline derivatives. ${ }^{61}$

A solvent-free approach for the preparation of quinolines (93) was disclosed by Soleimani et al. (Scheme 33). In this approach, 2-aminoaryl ketones (106) undergoes Friedlander annulations with $\alpha$-methylene ketones (95) using catalytic amount of $\mathrm{Cu}(\mathrm{OTf})_{2}$ at room temperature to afford wide range of quinolines and poly-substituted quinolines. Further the developed methodology avoided the use of both harsh conditions and hazardous acids or bases. ${ }^{62}$

Modified Friedlander synthesis of quinolines (108) was achieved by Cho and co-workers by using copper and $\mathrm{KOH}$ with either PEG 2000 or MS 4A via oxidation of 2-aminobenzyl alcohol (75) followed by coupling and cyclization with a wide range of ketones/secondary alcohols (107) under $\mathrm{O}_{2}$ atmosphere (Scheme 34). The advantage of this protocol is reusability of catalyst as it can be reused for 10 times without appreciable loss in its activity. ${ }^{63}$

A ruthenium based catalyzed new and improved pathway for the synthesis of quinolines was established by Mierde et al., through modified Friedlander condensation. In this method, 2-aminobenzyl alcohol (75)

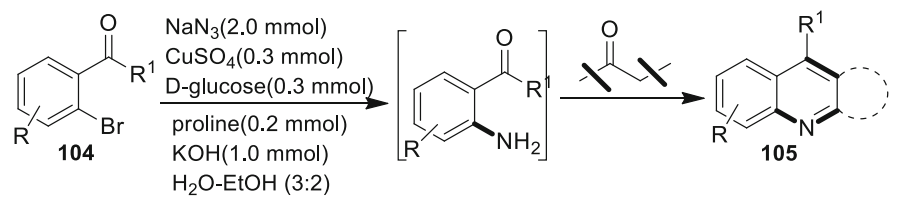

Scheme 32. Domino synthesis of quinoline derivatives using $\mathrm{CuSO}_{4}$-D-glucose catalyst. 


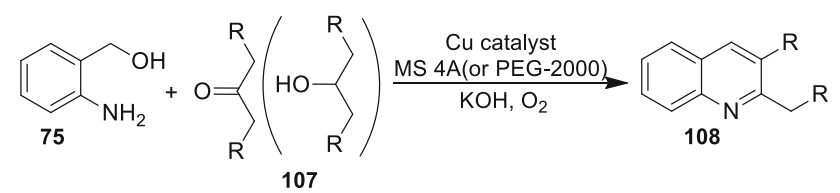

Scheme 34. Copper catalyzed preparation of quinoline derivatives.

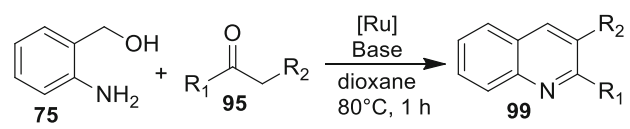

Scheme 35. Ruthenium catalyzed synthesis of quinolines from ketones and 2-aminobenzyl alcohol.

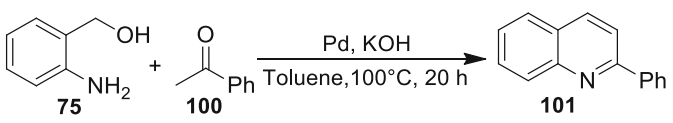

Scheme 36. Palladium-KOH catalyzed synthesis of quinoline derivatives under aerobic conditions.

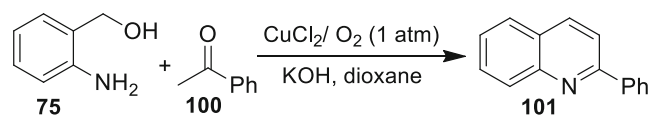

Scheme 37. $\mathrm{CuCl}_{2}$ and $\mathrm{KOH}$ catalyzed synthesis of quinoline derivatives.

undergoes oxidative cyclization with ketone (95) in presence of second generation Grubb's catalyst and its analogues at $80^{\circ} \mathrm{C}$ to afford desired quinolines (99) in good yields (Scheme 35). ${ }^{64}$

A modified Friedlander synthesis catalyzed by Palladium-KOH was disclosed by Cho and colleagues to afford the desired quinolines (101) from 2-aminobenzyl alcohol (75) and ketones (100) at $100{ }^{\circ} \mathrm{C}$ under aerobic conditions (Scheme 36). The advantage of this process is use of recyclable catalyst which can be used up to five times without any loss of activity. ${ }^{65}$

A simple and cost-effective protocol was demonstrated for the synthesis of quinolines derivatives (101) by the reaction of 2-aminobenzyl alcohol (75) and aldehydes (100)/ketones in dioxane at $100{ }^{\circ} \mathrm{C}$ under oxygen atmosphere in presence of $\mathrm{CuCl}_{2}$ and $\mathrm{KOH}$ as efficient catalytic system. The reaction proceeded through oxidative coupling and cyclization with range of aldehydes and ketones under oxygen atmosphere (Scheme 37). ${ }^{66}$

A recyclable yttrium triflate catalyzed mild and highly efficient, one-pot methodology was introduced by De et al. (Scheme 38). In this method, 2-aminoaryl ketones (110) undergoes reaction with $\alpha$-methylene ketones (95) via Friedlander annulations at ambient temperature to form the desired quinolines (111) in excellent yields. ${ }^{67}$

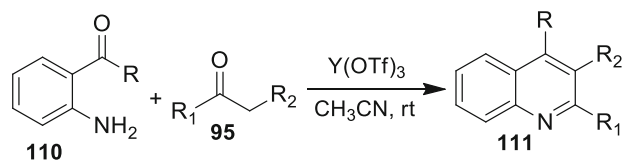

Scheme 38. One-pot approach to quinolines using $\mathrm{Y}(\mathrm{OTf})_{3}$ catalyst.

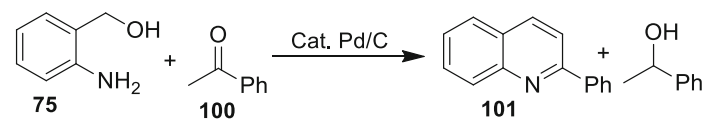

Scheme 39. Oxidative coupling of 2-aminobenzyl alcohol and ketones for synthesis of quinolines.

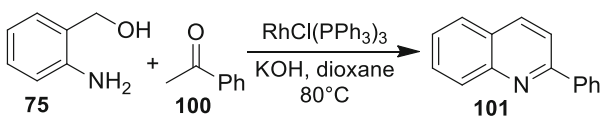

Scheme 40. $\mathrm{RhCl}\left(\mathrm{PPh}_{3}\right)_{3}$ and $\mathrm{KOH}$ catalyzed synthesis of quinolines.

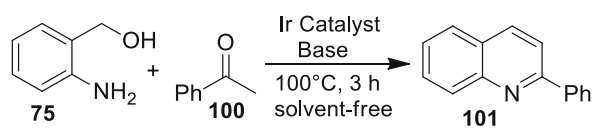

Scheme 41. $\left[\mathrm{IrCl}(\operatorname{cod})_{2}\right] / \mathrm{IrCl}_{3}$ catalyzed synthesis of quinolines under neat condition.

To the various modification introduced in the Friedlander synthesis for the generation of quinolines (Scheme 39), another $\mathrm{Pd} / \mathrm{C}$ together with $\mathrm{KOH}$ catalyzed modification leading to the desired quinolines (101) from 2-aminobenzyl alcohol (75) and ketones (100) in dioxane at $100{ }^{\circ} \mathrm{C}$ was introduced. ${ }^{68}$

Another modification in the Friedlander synthesis using $\mathrm{RhCl}\left(\mathrm{PPh}_{3}\right)_{3}$ and $\mathrm{KOH}$ as catalyst was reported by Cho and colleagues. In this process 2-aminobenzyl alcohol (75) initially undergoes oxidation to give $o$ aminobenzaldehyde which subsequently undergoes cross aldol reaction with a wide variety of ketones (100) followed by dehydration to afford the corresponding quinolines (101) in moderate to good yields (Scheme 40). ${ }^{69}$

Another modification of the Friedlander synthesis was reported by Taguchi et al., producing suitably substituted quinolines (101). In this protocol 2-aminobenzyl alcohol (75) undergoes reaction with 2equivalent of ketones (100) utilizing catalytic amount of $\left[\mathrm{IrCl}(\operatorname{cod})_{2}\right]$ or $\mathrm{IrCl}_{3}$ and $\mathrm{KOH}$ without using any solvent (Scheme 41). Further, the catalyst was effectively utilized for the synthesis of pyrrole. ${ }^{70}$

An improved variant of Friedlander pathway was demonstrated by McNaughton et al., for the synthesis of quinolines (46) directly from $o$-nitrobenzaldehyde 


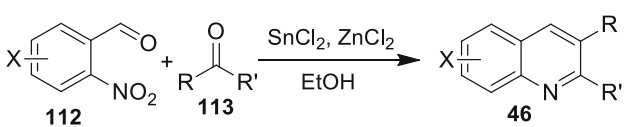

Scheme 42. $\mathrm{SnCl}_{2}$ and $\mathrm{ZnCl}_{2}$ catalyzed Friedlander synthesis of quinolines from $o$-nitrobenzaldehyde.

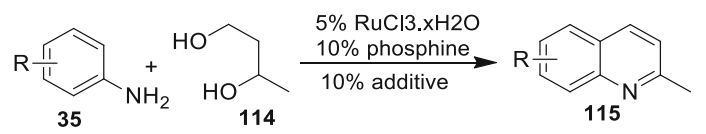

Scheme 43. Ruthenium catalyzed synthesis of 2- and 3-substituted quinolines.

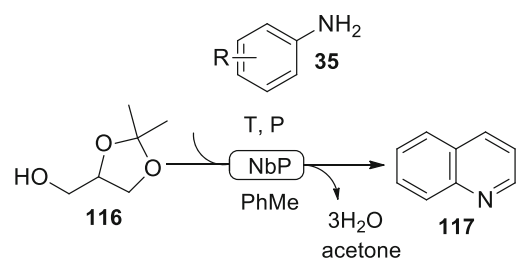

Scheme 44. Niobium phosphate catalyzed Skraup synthesis of quinoline derivatives.

(112) and carbonyl compound (113) thus obviating the requirement of isolation and purification of $o$ aminobenzaldehyde (Scheme 42). This high-yielding process utilizes $\mathrm{SnCl}_{2}$ and $\mathrm{ZnCl}_{2}$ as a mild and efficient catalytic system. ${ }^{71}$

Ruthenium catalyzed straightforward approach was explored via single step cyclocondensation of anilines (35) with 1,3-diols (114) for the generation of substituted quinolines (115) as shown in (Scheme 43). The reaction was performed by employing catalytic amounts of $\mathrm{RuCl}_{3} \cdot \mathrm{xH}_{2} \mathrm{O}, \mathrm{PBu}_{3}$ and $\mathrm{MgBr}_{2} \cdot \mathrm{OEt}_{2}$ to generate variety of 2- and 3-substituted quinolines and only water and dihydrogen was obtained as by-products under this protocol. Further, it was believed that 1,3-diol initially undergoes dehydrogenation to form 3-hydroxyaldehyde which subsequently loses water molecule to form $\alpha, \beta$ unsaturated aldehyde which finally undergoes reaction with aniline to give the desired product. ${ }^{72}$

Niobium phosphate catalyzed modified Skraup synthesis was introduced by Jing et al., resulting in synthesis of quinolines (117) via continuous reaction of solketal (116) with varied aromatic amines (35) (Scheme 44). Further, the method which worked at $250^{\circ} \mathrm{C}$ and $10 \mathrm{MPa}$

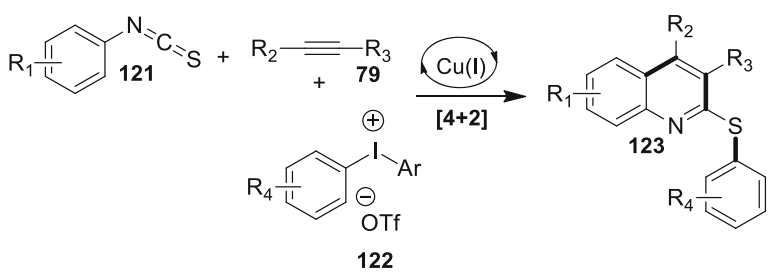

Scheme 46. Cu-catalyzed regioselective synthesis of 2-arylthio quinolines.

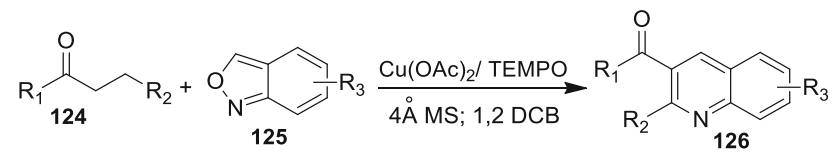

Scheme 47. $\mathrm{Cu}$ catalyzed one-pot synthesis of 3-keto quinolines.

pressure was successfully applied to get both mono- and bis-quinoline. ${ }^{73}$

An improved Rhodium catalyzed two-component synthesis of quinolines (120) in basic medium was devised (Scheme 45). This modified reaction was complementary in regioselectivity to the conventional Skraup-Doebner-Von Miller synthetic mode and exhibit the reaction between $\alpha, \beta$-unsaturated ketones (119) and $o$-aminophenylboronic acid derivatives (118). ${ }^{74}$

A regioselective $\mathrm{Cu}$-catalyzed multi-component cascade cyclization reaction for the synthesis of pharmaceutically important 2-arylthio quinolines (123) was demonstrated by Khan et al. (Scheme 46). The reaction proceeded via intermolecular annulation of aryl isothiocyanates (121), alkynes (79) and iodonium salts (122) to give diversely functionalized quinolones in good to excellent yield. Further, the developed protocol showed great tolerance towards varied functional group. ${ }^{75}$

Tiwari et al., have demonstrated an efficient, onepot approach to synthesize substituted quinolines (126) from easily accessible saturated ketones (124) with anthranils (125) (Scheme 47). In this one-pot, atomeconomic cascade reaction, copper catalyzed dehydrogenation of saturated ketones lead to the in situ generation of $\alpha, \beta$-unsaturated ketones which is then made to react with the anthranils producing quinolines through aza-Michael addition via amination followed by annulation. ${ }^{76}$

A copper or palladium catalyzed, oxidative cyclization of aromatic enamines (127) with alkynes or alkenes

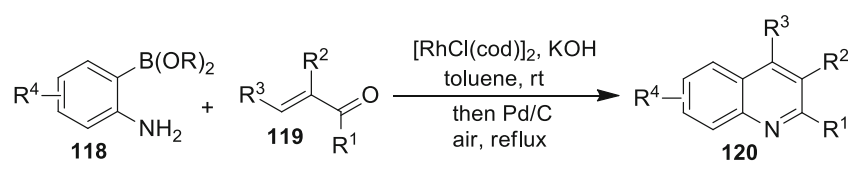

Scheme 45. Rh-catalyzed synthesis of quinolines in basic medium. 


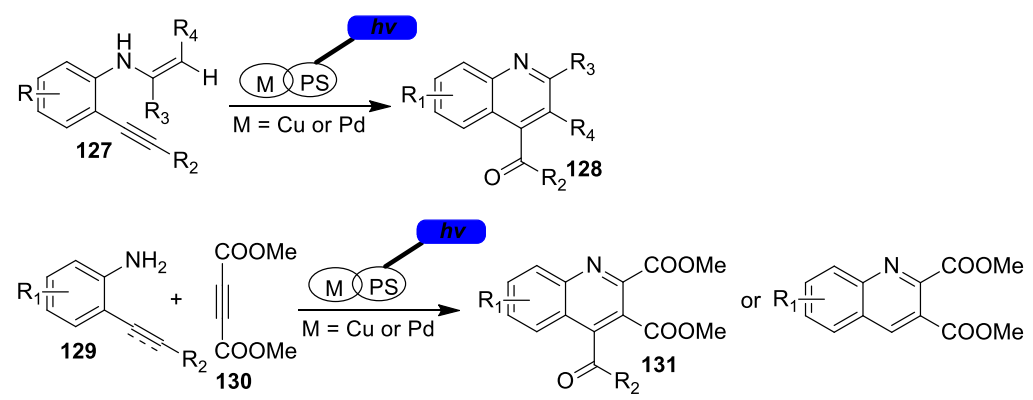

Scheme 48. Dual transition metal-visible light photo-redox catalyzed synthesis of multisubstituted quinolines.

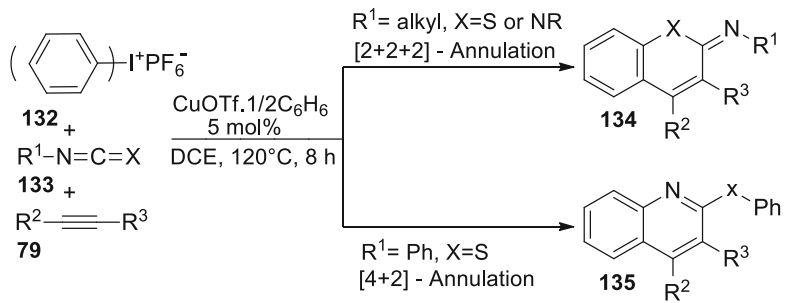

Scheme 49. CuOTf catalyzed cascade synthesis of quinolines.

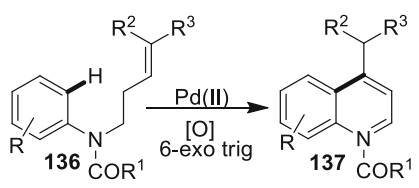

Scheme 50. Palladium catalyzed synthesis of quinoline derivatives.

under mild conditions was described by Xia and coworkers. This transformation was preceded by dual transition metal-visible light photo-redox catalyzed process in presence of dioxygen as an oxygen source to furnish multisubstituted quinoline derivatives $(\mathbf{1 2 8 , 1 3 1 )}$ (Scheme 48). Following this approach, quinolines have been accessed in good to moderate yields through sequential formation of $\mathrm{C}-\mathrm{C}$ and $\mathrm{C}-\mathrm{O}$ bonds. This approach was further extended to the amino alkynes (129) for intermolecular oxidative cyclization with alkynes (130). ${ }^{77}$

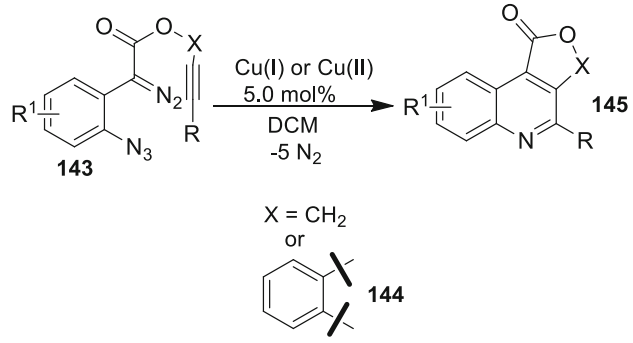

Scheme 52. Copper catalyzed synthesis of 4-carboxyl quinolines.

Chi et al., investigated cascade synthesis of quinolines by $[2+2+2]$ and [4+2] annulation reactions of heterocumulenes (133), alkynes (79), and diaryliodonium salts (132). The overall process is accomplished by using CuOTf as catalyst for generating final products in good yield with excellent selectivity (Scheme 49). This protocol also provides a new route to activate heterocumulenes by a unique highly reactive cationic intermediate. $^{78}$

Menoyo et al., introduced palladium catalyzed intramolecular $\mathrm{C}-\mathrm{H}$ alkenylation strategy for the preparation of quinolines (137) and 1, 2-dihydroquinolines (136) (Scheme 50). The proposed atom-economic dehydrogenative coupling leads to selective synthesis of quinolines in moderate to good yields. ${ }^{79}$

A series of polysubstituted quinolines $(\mathbf{1 4 1 , 1 4 2})$ were easily prepared from anilines (138), aldehydes (41) and alcohols $(\mathbf{1 3 9 , 1 4 0 )}$ under mild conditions via sequential formation of two C-C bonds (Scheme 51). The utility of

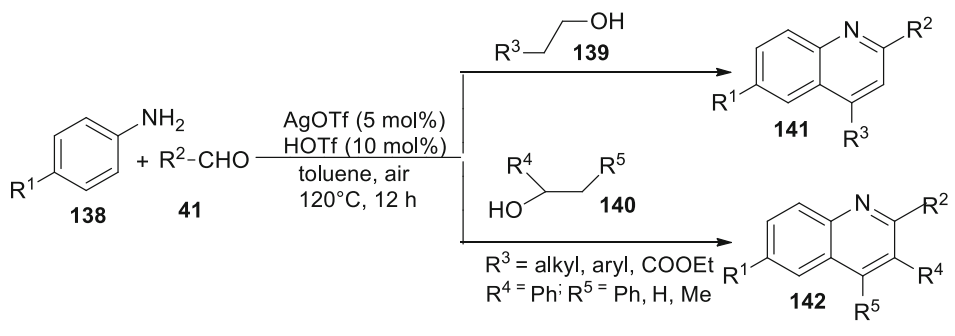

Scheme 51. Silver catalyzed synthesis of polysubstituted quinolines. 


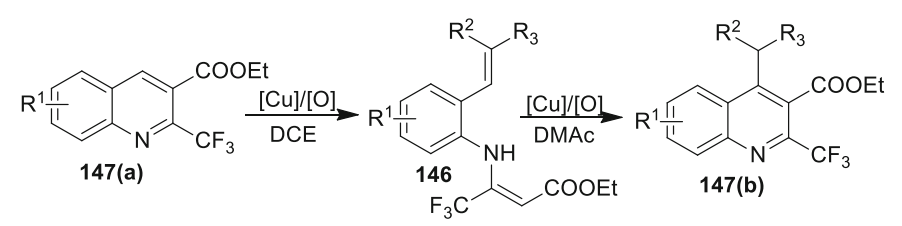

Scheme 53. Copper catalyzed synthesis of 2-trifluoromethylquinolines.

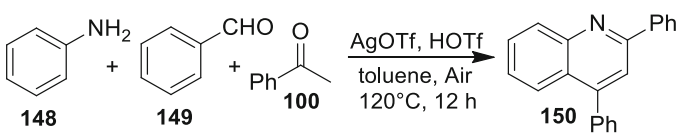

Scheme 54. Silver catalyzed one-pot synthesis of quinolines.

this reaction lies in the broad range of substrates including aliphatic alcohols, aryl alkanols, cycloalkanols, and ethylene glycol thereby generating a wide variety of products. ${ }^{80}$

A much improved spectacular example of multisubstituted 4-carboxyl quinoline's (145) preparation using copper catalyst was presented (Scheme 52). In this alkyne metathesis cascade reaction, alkyne serves as a di-functional unit forming one $\mathrm{C}=\mathrm{N}$ and one $\mathrm{C}=\mathrm{C}$ bond on each carbon with azide (143) and diazo (143) groups respectively and giving the requisite product in excellent yields. ${ }^{81}$

Intramolecular oxidative cyclization of $\mathrm{N}$-(2-alkenylaryl) enamines (146), in presence of copper leads to the generation of 2-trifluoromethylquinolines (147(a) and 147(b) via domino intramolecular oxidative cyclization (Scheme 53). ${ }^{82}$

Another interesting atom-economic silver catalyzed approach was described. This process involved construction of polysubstituted quinolines (150) from arylamines (148), aldehydes (149), and ketones (100) or arylamines and 1, 3-diketones (Scheme 54). This strategy provides a straightforward eco-friendly route to synthesize complex quinoline moieties from readily available starting materials. ${ }^{83}$

A range of differently substituted quinolines (153) were prepared from glycine esters (151) and simple alkenes (152) via aerobic oxidative dehydrogenative coupling/aromatization using visible-light (Scheme 55).

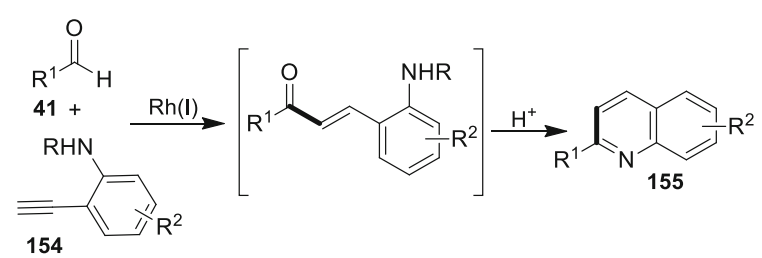

Scheme 56. Rh-catalyzed construction of quinolines.

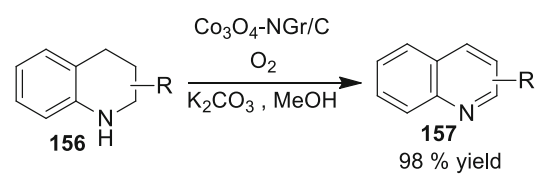

Scheme 57. Synthesis of 1,2,3,4-tetrahydroquinolines using cobalt oxide catalyst.

This simple and convenient reaction proceeds with the capability of wide substrate tolerance. ${ }^{84}$

An elegant Rh-catalyzed hydroacylative addition of aldehydes (41) and $o$-alkynyl anilines (154) leading to 2-aminophenyl enones and finally to substituted quinolines (155) was described by Neuhaus and co-workers (Scheme 56). This methodology has the advantage of high functional group tolerance thus allowing rapid synthesis of libraries of diversely substituted quinoline architectures. ${ }^{85}$

Aerobic dehydrogenation of 1,2,3,4-tetrahydroquinolines (156), using heterogeneous cobalt oxide catalyst enabled an efficient route for the generation of corresponding quinolines (157) under mild conditions (Scheme 57). Application of $\mathrm{Co}_{3} \mathrm{O}_{4}$ catalyst further aids in aerobic dehydrogenation process. ${ }^{86}$

Kong et al., devised a copper-catalyzed methodology generating a wide array of functionalised quinolines (159) through intermolecular Ullmann-type electrocyclization reaction. For this purpose, $o$-acylanilines $(\mathbf{6 5})$

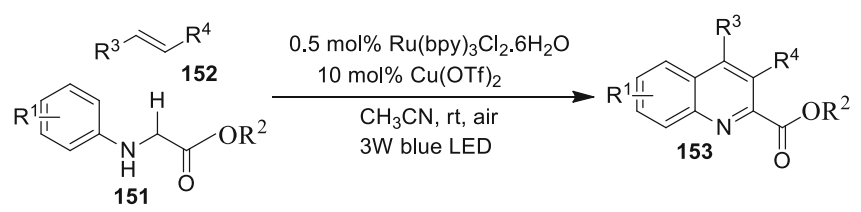

Scheme 55. Visible light induced photocatalytic synthesis of quinolines under aerobic conditions. 


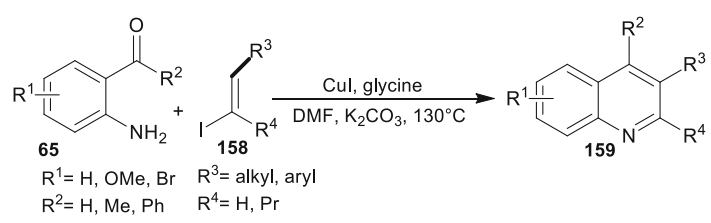

Scheme 58. Copper-catalyzed Ullmann-type reaction for the generation of quinolines.

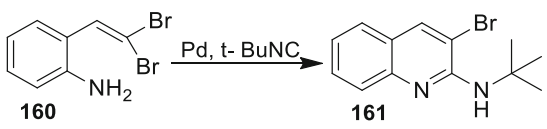

Scheme 59. Palladium catalyzed synthesis of 2-amino-3-bromoquinolines.

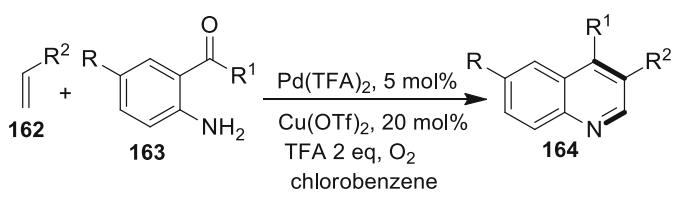

Scheme 60. Preparation of 3, 4-disubstituted quinolines palladium catalyst.

and alkenyl iodides (158), were employed. The desired transformation took place by following oxidative addition, reductive elimination, intramolecular cyclization and aromatization steps (Scheme 58). The reaction has the advantage of increased efficiency, mild reaction conditions, easy operation, and broad functional-group tolerance. ${ }^{87}$

In the presence of palladium, a tandem isocyanide insertion followed by intramolecular cyclization of $\mathrm{gem}$ dibromovinylanilines (160) in 1,4-dioxane provided new and efficient methodology for the generation of 2amino-3-bromoquinolines (161) (Scheme 59). ${ }^{88}$

A novel catalytic route leading regioselective generation of 3,4-disubstituted quinolines (164) from readily available simple alkenes (162) and $o$-acyl anilines (163) under palladium catalysis via anti-Markovnikov selectivity was reported (Scheme 60). ${ }^{89}$

Zhang et al., explored $\mathrm{FeCl}_{3}$ catalyst for the synthesis of diverse 3 -arylquinolines (166). In this approach, anilines (35) undergoes domino reaction with styrene oxides (165) followed by the cleavage of $\mathrm{C}-\mathrm{C}$ bond and $\mathrm{C}-\mathrm{H}$ activation from easily available raw material (Scheme 61). The summarized protocol was simple to obtain 3-arylquinolines in good yield. ${ }^{90}$

Copper catalyzed aerobic synthetic methodology of multi-substituted quinolines (168) from N-(2-alkynylaryl) enamine carboxylates (167) (Scheme 62) was achieved. The transformation took place through intramolecular carbo-oxygenation of alkynes. Imidazole and

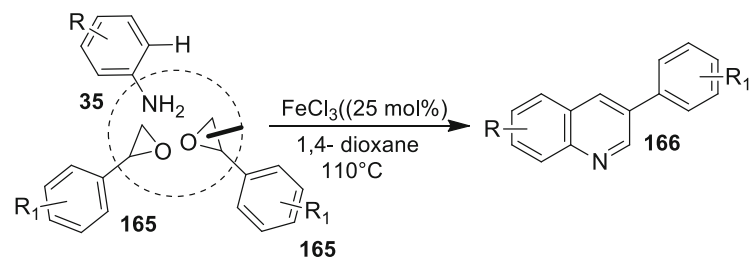

Scheme 61. Fe catalyzed synthesis of 3-arylquinolines from anilines and styrene oxides.

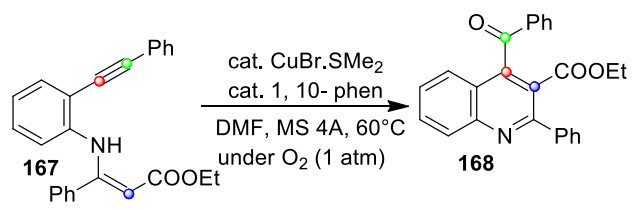

Scheme 62. Copper catalyzed synthesis of highly substituted quinolines.

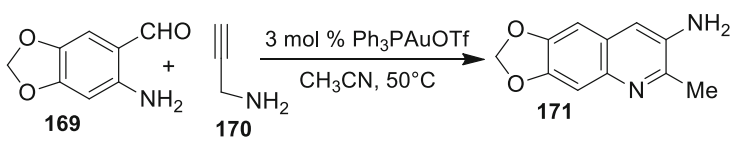

Scheme 63. Gold(I) catalyzed synthesis of 3-aminoquinolines.

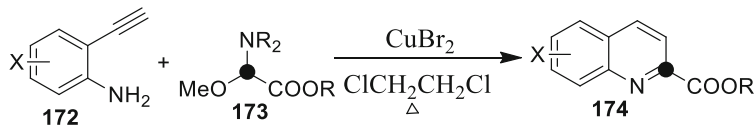

Scheme 64. Synthesis of quinolines from NO-acetal and 2-ethnylanilines.

quinazoline derivatives were also synthesized by applying this strategy. ${ }^{91}$

A series of 3-aminoquinolines (171) was synthesized via one-pot approach of easily accessible 2aminobenzaldehyde (169) and propargyl amine (170) using $\mathrm{Ph}_{3}$ AuOTf catalyst (Scheme 63). Importantly, 3aminoquinolines is not an easily accessible class of materials and can be utilized as building blocks to synthesize functionalized quinoline. ${ }^{92}$

Sakai et al., has disclosed a new approach which involves copper-catalyzed [5+1] annulations of 2-ethnylanilines (172) with N,O-acetal (173) to generate substituted quinoline (174). The method was further extended for [5+1] annulations with 2-ethnylanilines and ethyl glyoxylates utilizing combo $\mathrm{CuBr}_{2}$-TFA catalytic system to afford quinoline skeleton (Scheme 64). ${ }^{93}$

A facile and effective approach was developed to synthesize differently substituted quinoline (42). In this protocol, 2-aminophenyl-1-en-3-ols (175) undergoes intramolecular allylic amination to get the target product. This conversion was completed using $2 \mathrm{~mol} \% \mathrm{FeCl}_{3}$ to afford excellent yields of quinolines (Scheme 65). ${ }^{94}$ 


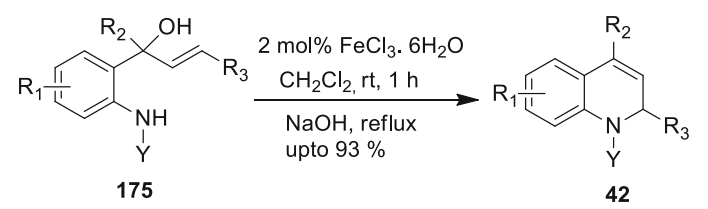

Scheme 65. $\mathrm{FeCl}_{3}$ catalyzed synthesis of quinolines .

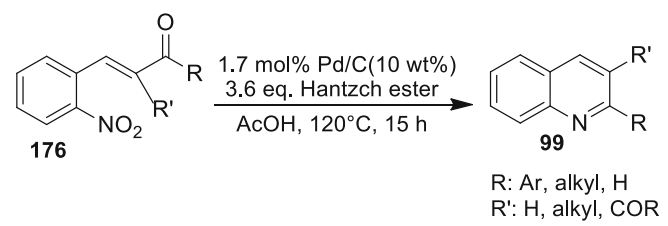

Scheme 66. Chemo-selective approach for the synthesis of substituted quinolines.

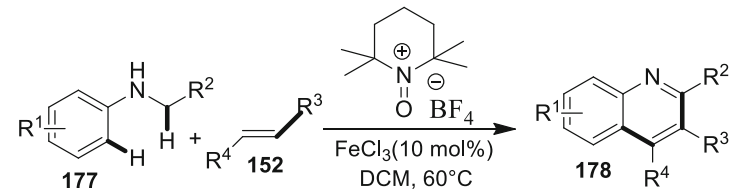

Scheme 67. Iron (III) chloride catalyzed synthesis of quinolines.

A facile, effective and chemo-selective approach was developed by Xing and colleagues for the synthesis of substituted quinoline (99). The synthesis of target quinolines were achieved by the reduction of nitroarenes using Hantzsch ester as reducing agent (176) in presence of $\mathrm{Pd} / \mathrm{C}$ catalyst (Scheme 66). The HEH acts both as the reductant and the modifier of the palladium surface. The high yield obtained in this protocol makes this protocol a remarkable approach for the synthesis of substituted quinolines. ${ }^{95}$

A convenient and inexpensive approach catalyzed by iron(III) chloride and TEMPO oxoammonium salt as an innocuous oxidant for the preparation of wide range of substituted quinolines was reported (Scheme 67). This Povarov-type reaction allows dehydrogenation of $\mathrm{N}$ alkyl anilines(177) with mono- and 1, 2-disubstituted aryl and alkyl olefins (152). In this conversion, TEMPO oxoammonium salt plays a major role in dehydrogenation of tetrahydroquinolines to final quinoline derivatives (178). ${ }^{96}$

An operationally simple cycloisomerization tandem methodology was discovered by employing $\mathrm{CuI}$ and pyrrolidine cooperative catalysts to furnish 2-substituted quinolines (181) from 2-aminobenzaldehydes (179) and alkynes (180) (Scheme 68). In this reaction, application of either of the catalysts alone couldn't afford the product and thus both the catalysts proved vital in the final conversion process. ${ }^{97}$

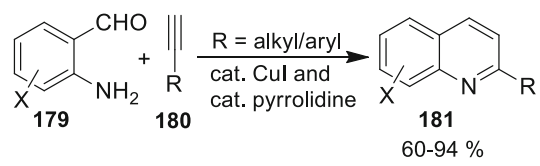

Scheme 68. Synthesis of 2-substituted quinolines by $\mathrm{CuI}$ and pyrrolidine catalysts.

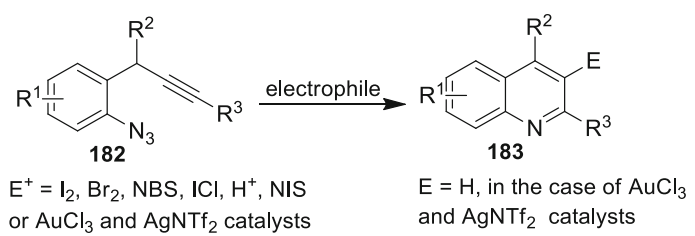

Scheme 69. Synthesis of substituted quinolines via electrophilic cyclization of 1-azido-2-(2-propynyl) benzene.
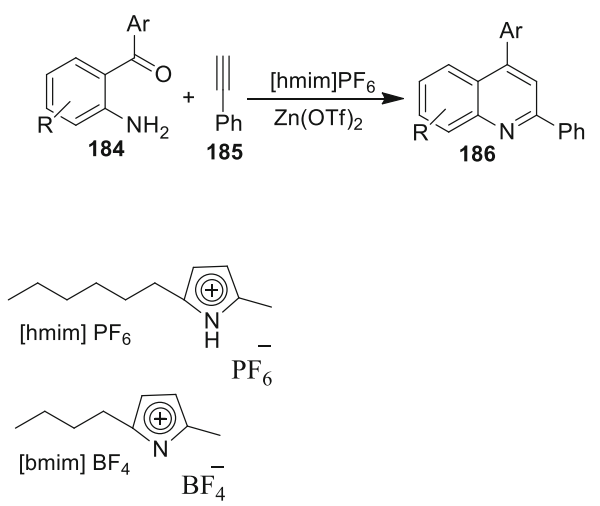

Scheme 70. Ionic liquid catalyzed synthesis of 2, 4-disubstituted quinolines.

An unprecedented synthesis of substituted quinolines (183) from suitable substrates via intramolecular electrophilic cyclization was devised. In presence of electrophilic reagents $\left(\mathrm{I}_{2}, \mathrm{Br}_{2}, \mathrm{ICl}, \mathrm{NBS}\right.$, NIS and HNTf $_{2}$ ), 1-azido-2-(2-propynyl)benzene (182) undergoes intramolecular electrophilic cyclization under mild conditions in $\mathrm{CH}_{3} \mathrm{NO}_{2}$ or through catalysis with $\mathrm{AuCl}_{3}$ / $\mathrm{AgNTf}_{2}$ in THF at $100{ }^{\circ} \mathrm{C}$ forming the desired quinolines (Scheme 69). ${ }^{98}$

A facile, environmentally benign route was developed for generating a series of substituted quinolines. Here 2-aminoaryl ketones (184) and phenylacetylenes (185) interacted via Meyer-Schuster rearrangement in presence of zinc trifluoromethanesulfonate (Scheme 70). In this protocol, ionic liquid [hmim] $\mathrm{PF}_{6}$ was applied as a promoter to accomplish the synthesis of final desired product (186). ${ }^{99}$

Zhang and co-workers described Aza-Wacker oxidative cyclization approach for the development of 2methylquinolines (188) using aniline derivative (187) 


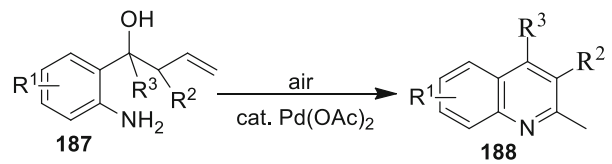

Scheme 71. Synthesis of 2-methylquinolines via Aza-Wacker oxidative cyclization.

in presence of palladium as catalyst (Scheme 71). This work was executed in the presence of air under mild conditions. ${ }^{100}$

6-endo-dig cyclization-dehydration was carried for regioselective synthesis of substituted quinolines (190) from 1-(2-aminoaryl)-2-yn-1-ols (189) (Scheme 72). This reaction was mediated by copper or palladium catalyst affording product in good to excellent yields. The crude substrates required for the synthesis of quinolines were generated by reacting alkynylmagnesium bromide and 2-aminoaryl ketones. ${ }^{101}$

$\mathrm{Au}$ (I)-catalyzed tandem hydroamination-hydroarylation reaction synthesized suitably substituted 1,2dihydroquinolines (192) from primary aryl amines (35) and alkynes (191) and quinolines (194) from 2aminoaryl ketones (193) and alkynes (191) efficiently under microwave conditions (Scheme 73). The reaction showed compatibility with large number of substrates giving efficient output and required a short reaction time (10-70 $\mathrm{min}){ }^{102}$

A simple, efficient silver-catalyzed route with a broad substrate scope to synthesize quinolines was reported (Scheme 74). ${ }^{103}$ In this method, 2-aminobenzophenone (103) is made to react with ethyl acetoacetate (195) in

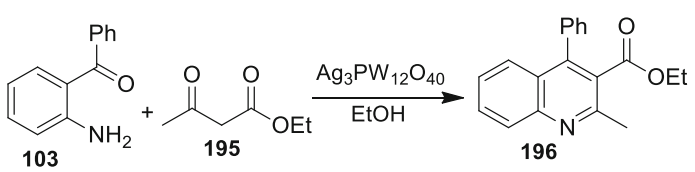

Scheme 74. Synthesis of quinolines employing silver phosphotungstate.

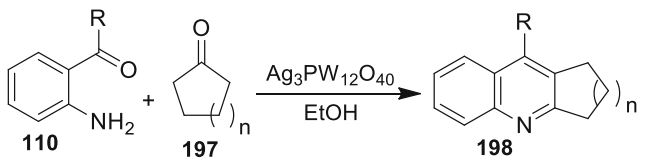

Scheme 75. Synthesis of tricyclic quinolines.

presence of catalytic amount of silver salt of heteropoly acid $\left(\mathrm{Ag}_{3} \mathrm{PW}_{12} \mathrm{O}_{40}\right)$ forming ethyl 2-methyl-4-phenyl3-quinoline carboxylate (196) in excellent yields. This methodology was further extended for the generation of suitable tricyclic quinolines (198) using cyclic ketones (197) such as cyclopentanone and cyclohexnone (Scheme 75). ${ }^{103}$

A simple, improved and efficient iron-catalyzed route generating 3-substituted quinolines (200) in presence of catalytic amount of ${ }^{6}\left[\mathrm{Cp} * \mathrm{Fe}(\mathrm{CO})_{2}\right]_{2}$ was devised through reductive cyclization of $o$-nitro-substituted Baylis-Hillman acetates (199) in presence of carbon dioxide (Scheme 76). ${ }^{104}$

Hatano et al., devised a novel and efficient cationic BINAP Pd(II) catalyzed methodology generating asymmetric quinoline derivative (202) containing one quaternary carbon atom from 1,7-enynes (201) through

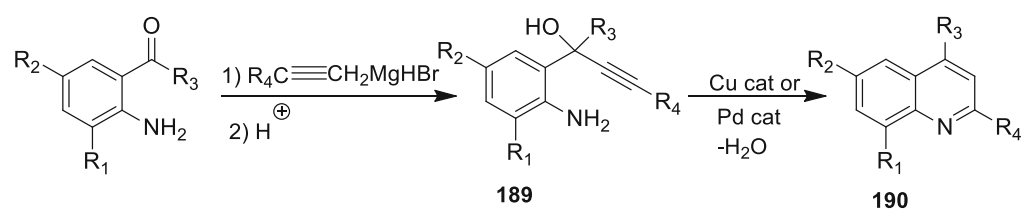

Scheme 72. Copper/palladium catalyzed synthesis of substituted quinolines.

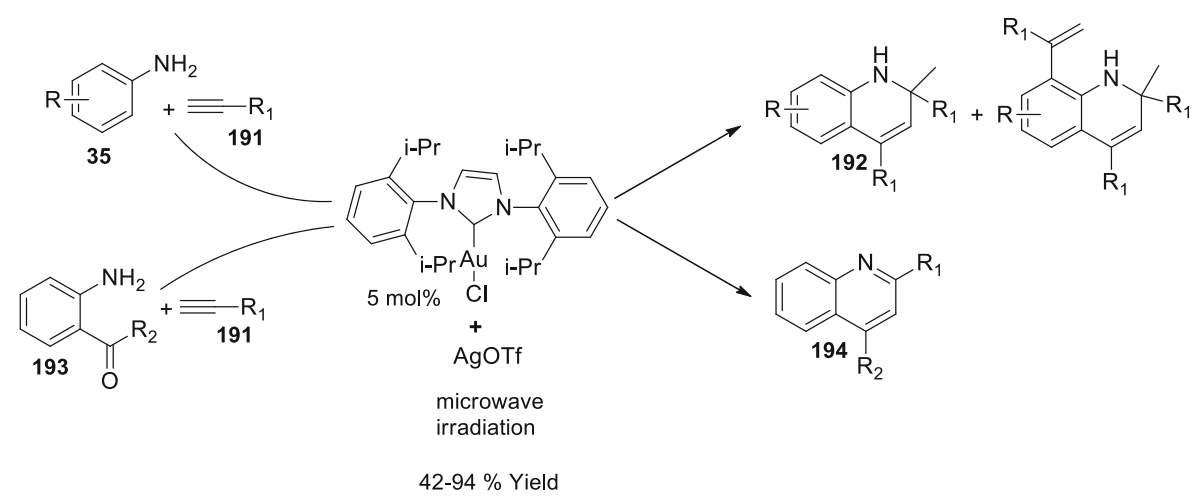

Scheme 73. Au (I)-catalyzed tandem synthesis of substituted 1,2-dihydroquinolines and quinolines. 


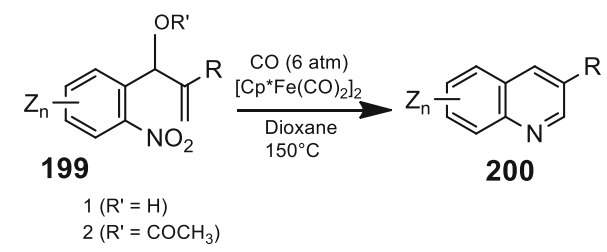

Scheme 76. Synthesis of 3-substituted quinolines using $\left[\mathrm{Cp} * \mathrm{Fe}(\mathrm{CO})_{2}\right]_{2}$ catalyst.

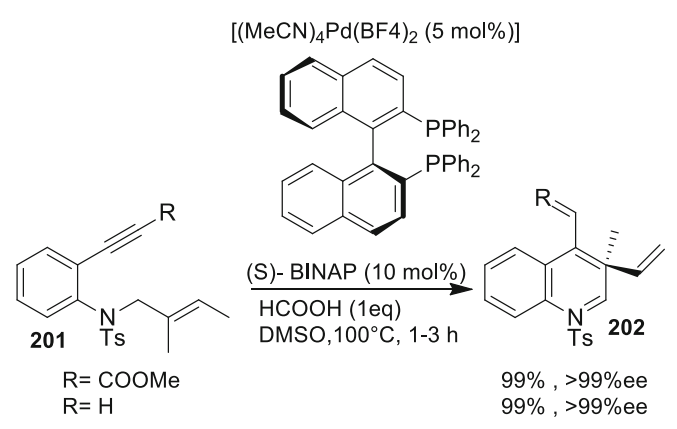

Scheme 77. Synthesis of quinoline derivatives by ene-type cyclization of 1,7-enynes.

ene-type cyclization (Scheme 77). The transformation proceeded in presence of $\mathrm{Pd}(\mathrm{II})$ catalyst such as $\left[(\mathrm{MeCN})_{4} \mathrm{Pd}\right]\left(\mathrm{BF}_{4}\right)_{2}$ together with S-BINAP as chiral bidentate PP-ligand and DMSO. ${ }^{105}$

Giorgio Abbiati et al., devised an eco-friendly multicomponent stereo-selective strategy for the synthesis of 2-aryl-4-amino quinolines (206) using 2-ethynylarylamines (172), aryl iodides (203), primary amines (204) and carbon-monoxide (205) in presence of palladium as a catalyst (Scheme 78). ${ }^{106}$ The reaction occurred through carbonylative coupling between aryl iodides and 2-ethynyl-arylamines (172) to form an intermediate which subsequently undergoes intra- and intermolecular addition reactions on carbon-carbon triple and carbon-oxygen double bonds to afford desired products in good yield.

Another significant and efficient mode for the generation of this quinoline scaffold was introduced by Anguille and co-workers as shown in Scheme 79. ${ }^{107}$ This synthetic route involves aniline (148) and $\mathrm{n}-\mathrm{Bu}_{3} \mathrm{~N}$ (207) for the generation of N-butylaniline (208) and 2propyl-3-ethylquinoline (209) in presence of platinum bromide via ortho-C-H activation of aromatic anilines.

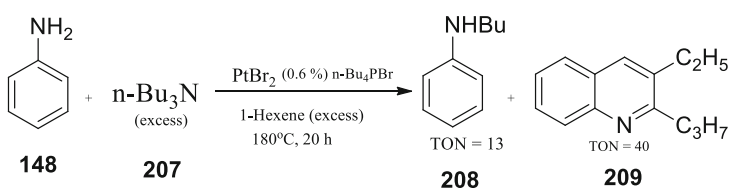

Scheme 79. Platinum-catalyzed sythesis of quinolines via $\mathrm{C}-\mathrm{H}$ activataion.

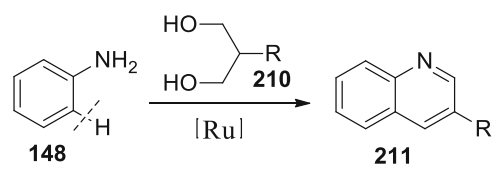

Scheme 80. Regioselective synthesis of quinoline.

Lee and Yi devised an efficient and green methodology forming the coveted product (211) using ruthenium complex as catalyst via $\mathrm{C}-\mathrm{H}$ coupling. This regioselective synthesis was done using arylamines (148) and 1, 3-diols (210) as shown (Scheme 80) without the formation of any by-products. ${ }^{108}$

Silver metal served as an efficient catalyst for the generation of quinolines $\mathbf{( 2 1 5 , 2 1 6 , 2 1 7 )}$ from $\mathrm{N}$-arylimines (212) and alkynes $\mathbf{( 7 8 , 2 1 3 , 2 1 4 )}$ through $\mathrm{C}-\mathrm{H}$ activation via oxidative coupling and cyclization processes (Scheme 81). ${ }^{109}$ This protocol worked well with both internal and terminal alkynes and also tolerated both electron withdrawing and electron releasing group on $\mathrm{N}$-arylimines to afford the diverse range of desired heterocyclic scaffolds.

Mohsenimehr and his co-workers introduced a new, efficient, less time-consuming and green methodology synthesizing pyrimido[4,5-b]quinolines (220) derivatives using aryl aldehyde (149), dimedone (219) and a suitable enamine (218) (Scheme 82). ${ }^{110}$ This multicomponent approach was carried out in presence of recyclable $\left[\gamma-\mathrm{Fe}_{2} \mathrm{O}_{3} @ \mathrm{HAp}-\mathrm{SO}_{3} \mathrm{H}\right]$ nanocatalyst. The recyclability of catalyst, mild reaction conditions, and excellent yield are the promising feature of this protocol.

Nickel-assisted sequential dehydrogenation and condensation approach for the synthesis of highly substituted quinolines (224) is reported. This protocol involves the reaction of both primary/secondary $\alpha$-2aminoaryl alcohols (221) either with ketones (222)/secondary alcohols (223) and occurred through C-N and C-C bonds formations using low catalytic loading

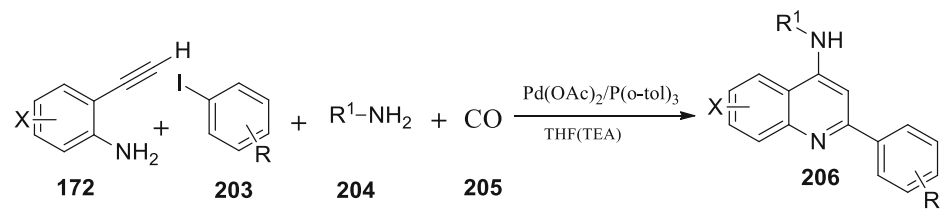

Scheme 78. Stereo-selective synthesis of 2-aryl-4-amino quinolines. 


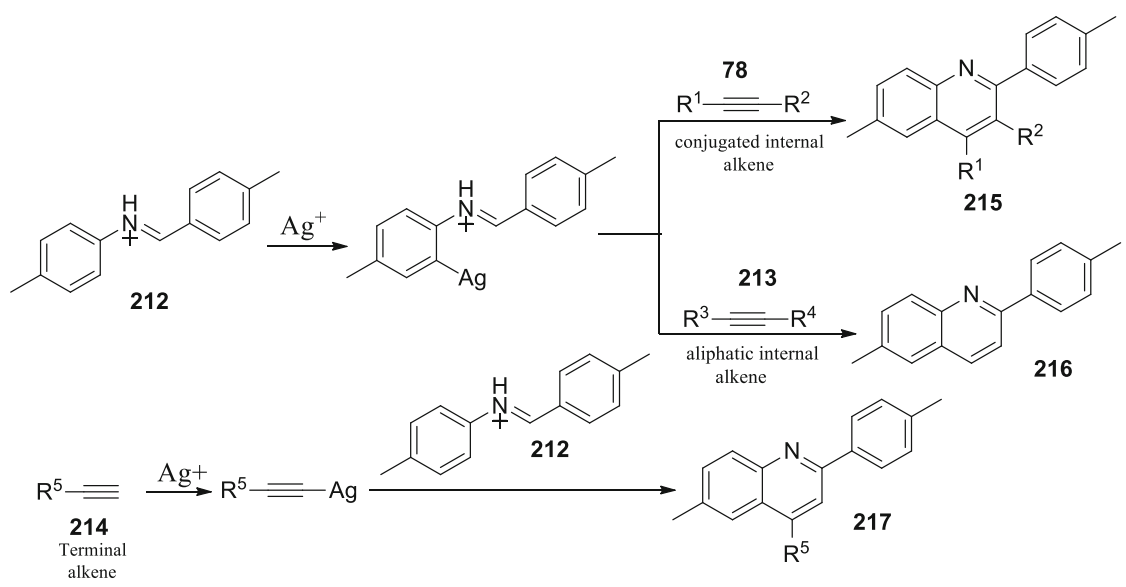

Scheme 81. Quinolines synthesis using N-arylimines and alkynes.

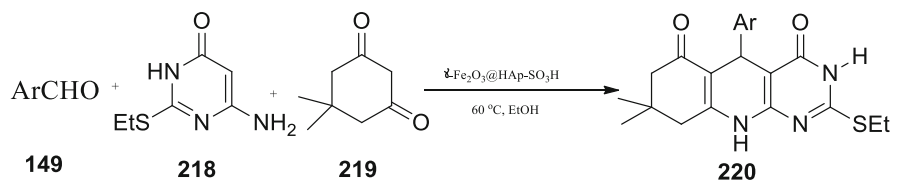

Scheme 82. Synthesis of pyrimido[4,5-b]quinolines.

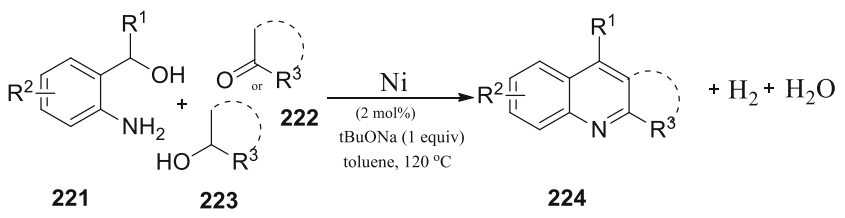

Scheme 83. Dehydrogenative strategy for the generation of quinolines.

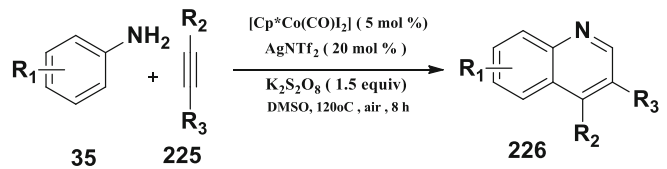

Scheme 84. One-pot Co(III)-catalyzed synthesis of quinolines involving DMSO.

(Scheme 83). ${ }^{111}$ This pathway is cost-effective, efficient and has good substrate scope to afford excellent yield of products. Further, the method is utilized to synthesize series of wide range of substituted quinolines.

$\mathrm{Xu}$ et al., demonstrated a $\mathrm{Co}(\mathrm{III})$-catalyzed new approach for the synthesis quinolines (226) in which DMSO is involved via $\mathrm{C}-\mathrm{H}$ activation/coupling of easily accessible anilines (35) with alkynes (225) (Scheme 84). ${ }^{112}$ In this reaction, DMSO not only acts as a solvent but also as $\mathrm{C}_{1}$ building block of the products. The added advantages of this procedure are the enhanced regioselectivity, use of non-toxic solvents and good to excellent yields.

Tan and colleagues reported a one-pot approach for the synthesis of quinolines (229) using the crosscoupling between the secondary alcohol (227) and

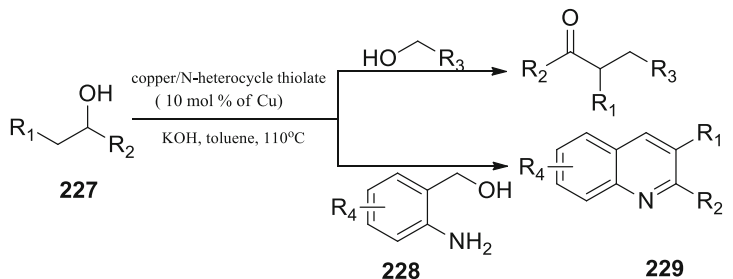

Scheme 85. One-pot $\mathrm{Cu}(\mathrm{I})$-catalyzed cross-coupling pathway forming quinolines.

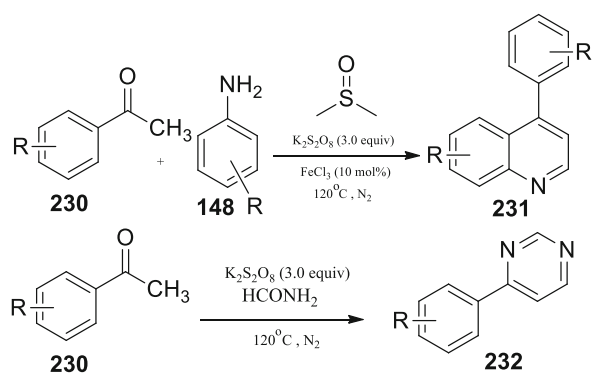

Scheme 86. Synthesis of quinolines and pyrimidines using oxidative annulation.

2-aminobenzyl alcohol (228) in presence of hexanuclear $\mathrm{Cu}(\mathrm{I})$ cluster of 4,6-dimethylpyrimidine-2-thiolate as bifunctional catalyst (Scheme 85). ${ }^{113}$ This methodology was also reported to produce $\alpha$-alkylated ketone and pyridines through the annulations reaction of secondary alcohol with primary alcohol and $\gamma$-amino alcohols respectively. 


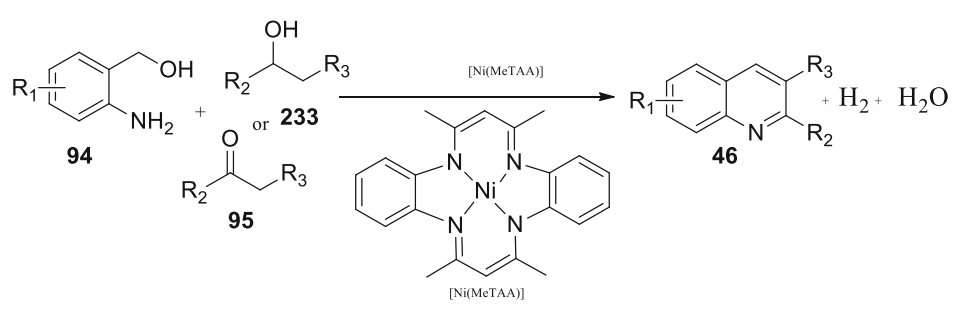

Scheme 87. One-pot nickel-catalyzed acceptorless dehydrogenative strategy.

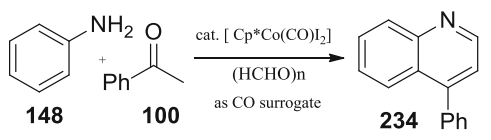

Scheme 88. Regioselective one-pot synthesis employing anilines and ketones.

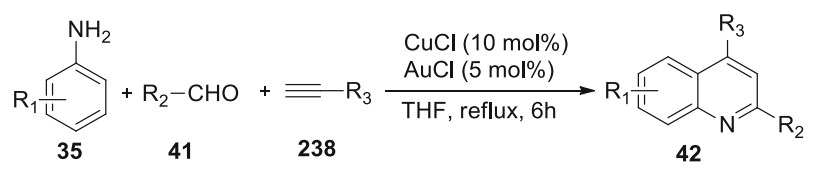

Scheme 90. Combo-catalytic strategy for the synthesis of 4-hydroxyalkyl-quinoline.
Recently, Jadhav and co-workers disclosed a procedure for the synthesis of quinolines (231) and pyrimidines (232) via oxidative annulations using anilines (148), aryl ketones (230) and DMSO as a methine equivalent (Scheme 86). ${ }^{114}$ The reaction was accelerated by $\mathrm{K}_{2} \mathrm{~S}_{2} \mathrm{O}_{8}$ and catalytic amount of $\mathrm{FeCl}_{3}$ was reported to produce the desired product in excellent yields. This cascade reaction occurred through the initial formation of the sulfenium ion followed by $\mathrm{C}-\mathrm{C}$ and $\mathrm{C}-\mathrm{N}$ bond generation and cyclization. The protocol was extended for the synthesis of 4-arylpyrimidines via activation of acetophenone-formamide conjugates. ${ }^{114}$

A series of substituted quinolines (46) was synthesized from $o$-aminobenzylalcohols (94) and ketones (95)/secondary alcohols (233) using nickel complex as catalyst (Scheme 87). ${ }^{115}$ This one-pot acceptorless dehydrogenative coupling strategy was established by Parua and co-workers in which nickel-catalyst [Ni(MeTAA)], initially catalyzed the dehydrogenation of alcohol succeeded by the cross-aldol condensation in basic medium which is followed by intramolecular cyclodehydration. The advantages of this method is that the catalyst is inexpensive, easy to synthesize and avoidance of hazardous oxidants.

A one-pot, $\mathrm{Co}(\mathrm{III})$ catalyzed operationally simple, eco-friendly and regioselective synthesis of diversely substituted quinolines (234) was described by $\mathrm{Xu}$ and co-workers (Scheme 88) by the reaction of anilines (148) and ketones (100). ${ }^{116}$ The reaction occurred via $\mathrm{C}-\mathrm{H}$ activation/carbonylation/cyclization in which paraformaldehyde was serving as the source of carbonyl for $\mathrm{C}_{1}$ framework of required product. Furthermore, this protocol is atom-economical, produces no harmful by-products and has the excellent functional group tolerance.

A novel and simple methodology for the synthesis of 2-substituted quinolines (237) was described by Jixiang and co-workers by the reaction 2-vinylanilines (235) and alkynoates (236) in presence of catalytic amount of Palladium (Scheme 89). ${ }^{117}$ The reaction proceeded via Michael addition followed by cyclization. Mechanistic studies revealed the interaction of enamine with the $\mathrm{Pd}$ catalyst, forming an intermediate which upon nucleophilic addition generates another intermediate which finally undergoes $\mathrm{C} \equiv \mathrm{C}$ cleavage to afford the desired quinoline.

Jiang et al., disclosed a combo-coupling strategy in which anilines (35) are made to react with aldehyde (41) and aliphatic alkynes (238) via sequential catalysis by $\mathrm{Cu}(\mathrm{I})$ and $\mathrm{Au}(\mathrm{I})$ resulted in the isolation of the 4hydroxyalkyl-quinoline (42) in good to excellent yields (Scheme 90). ${ }^{118}$

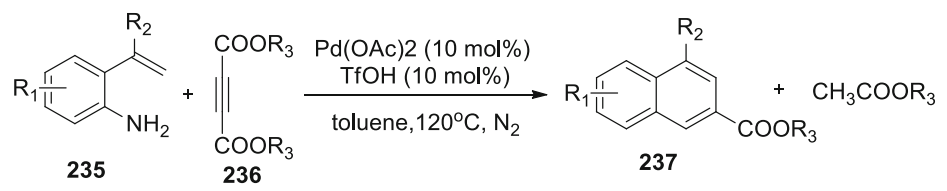

Scheme 89. One-pot Pd-catalyzed synthesis of 2-substituted quinolines. 


\section{Conclusions}

The biological applicability of this quinoline scaffold has raised the consciousness of the chemists towards the synthesis of this pharmacophore. Because of this, search for the development of efficient methodologies remains an active and emergent area of research. We herein compiled important transition-metal catalyzed strategies for the generation of quinoline in a comprehensive style after carrying out extensive survey of the literature. We believe that this review will definitely be helpful for the academicians and researchers to search for new and more efficient routes for the synthesis of quinoline based potential lead molecules which may further be exploited for discovery of drug molecules.

\section{Acknowledgements}

R. S. thanks SMVD University for fellowship.

\section{References}

1. (a) Zhao Y-L, Chen Y-L, Chang F-S and Tzeng CC 2005 Synthesis and cytotoxic evaluation of certain 4-anilino-2-phenylquinoline derivatives Eur. J. Med. Chem. 40 792; (b) Upadhayaya R S, Vandavasi J K, Vasireddy N R, Sharma V, Dixit S S and Chattopadhyaya J 2009 Design, synthesis, biological evaluation and molecular modelling studies of novel quinoline derivatives against Mycobacterium tuberculosis Bioorg. Med. Chem. 17 2830; (c) Shashikumar N D, Krishnamurthy G, Bhojyanaik H S, Lokesh M R and Jithendrakumara K S 2014 Synthesis of new biphenyl-substituted quinoline derivatives, preliminary screening and docking studies J. Chem. Sci. 126 205; (d) Faidallah H M, Khan K A and Asiri A M 2012 Synthesis of some new 2-oxo-1,4-disubstituted-1,2,5,6tetrahydrobenzo $[h]$ quinoline-3-carbonitriles and their biological evaluation as cytotoxic and antiviral agents J. Chem. Sci. 124625

2. (a) Jiang P, Zhu W, Gan Z, Huang W, Li J, Zeng $\mathrm{H}$ and Shi J 2009 Electron transport properties of an ethanol-soluble $\mathrm{AlQ}_{3}$-based coordination polymer and its applications in OLED devices J. Mater. Chem. 19 4551; (b) Liang F, Xie Z, Wang L, Jing X and Wang F 2002 New PPV oligomers containing 8-substituted quinoline for light-emitting diodes Tetrahedron Lett. 43 3427; (c) Ebenso E E, Obot I B and Murulana L C 2010 Quinoline and its derivatives as effective corrosion inhibitors for mild steel in acidic medium Int. J. Electrochem. Sci. 51574

3. (a) Sridhar P, Alagumuthu M, Arumugam S and Reddy S R 2016 Synthesis of quinoline acetohydrazidehydrazone derivatives evaluated as DNA gyrase inhibitors and potent antimicrobial agents $R S C A d v .6$ 64460; (b) Devi K, Asmat Y, Agrawal M, Sharma S and Dwivedi J 2013 Synthesis and evaluation of some novel precursors of oxozolidinone analogues of chloroquinoline for their antimicrobial and cytotoxic potential
J. Chem. Sci. 125 1093; (c) Desai N C, Rajpara K M, Joshi V V, Vaghani H V and Satodiya H M 2013 Synthesis, characterisation and antimicrobial screening of hybrid molecules containing quinoline, pyrimidine and morphine analogues J. Chem. Sci. 125 321; (d) Zhang G-F, Zhang S, Pan B, Liu X and Feng L-S 2018 4-Quinolone derivatives and their activities against Gram positive pathogens Eur. J. Med. Chem. 143 710

4. (a) Marganakop S B, Kamble R R, Hoskeri J, Prasad D J and Meti G Y 2014 Facile synthesis of novel quinoline derivatives as anticancer agents $\mathrm{Med}$. Chem. Res. 23 2727; (b) Lee E, Han S, Jin G H, Lee H J, Kim W-Y, Ryu J-H and Jeon R 2013 Synthesis and anticancer activity of aminodihydroquinoline analogs: Identification of novel proapoptotic agents Bioorg. Med. Chem. Lett. 23 3976; (c) Gopal M, Shahabuddin M S and Inamdar S V 2002 Interaction between an 8Methoxypyrimido [4',5':4,5] thieno(2,3-b) quinoline$4(3 \mathrm{H})$ one antitumour drug and deoxyribonucleic acid J. Chem. Sci. 114687

5. (a) Insuasty B, Montoya A, Becerra D, Quiroga J, Abonia R, Robledo S, Vélez I D, Upegui Y, Nogueras M and Cobo J 2013 Synthesis of novel analogs of 2-pyrazoline obtained from [(7-chloroquinolin-4yl)amino]chalcones and hydrazine as potential antitumor and antimalarial agents Eur. J. Med. Chem. 67 252; (b) Kumar A, Srivastava K, Kumar S R, Puri S K and Chauhan P M S 2010 Synthesis of new 4-aminoquinolines and quinoline-acridine hybrids as antimalarial agents Bioorg. Med. Chem. Lett. 20 7059; (c) Pretorius S I, Breytenbach W J, Kock C, Smith P J and N'Da D D 2013 Synthesis, characterization and antimalarial activity of quinoline-pyrimidine hybrids Bioorg. Med. Chem. Lett. 21 269; (d) Kaur K, Jain M, Reddy R P and Jain R 2010 Quinolines and structurally related heterocycles as antimalarials Eur. J. Med. Chem. 453245

6. (a) Baba A, Kawamura N, Makino H, Ohta Y, Taketomi S and Sohda T 1996 Studies on disease-modifying antirheumatic drugs: Synthesis of novel quinoline and quinazoline derivatives and their anti-inflammatory effect J. Med. Chem. 39 5176; (b) Bekhit A A, El-Sayed O A, Aboulmagd E and Park J Y 2004 Tetrazolo[1,5$a$ ]quinoline as a potential promising new scaffold for the synthesis of novel anti-inflammatory and antibacterial agents Eur. J. Med. Chem. 39249

7. $\mathrm{Hu} \mathrm{H}-\mathrm{Y}$ and Chen C-F $2006 \mathrm{~A}$ new fluorescent chemosensor for anion based on an artificial cyclic tetrapeptide Tetrahedon Lett. 47175

8. Aly M R E, Ibrahim M M, Okael A M and Gherbawy Y A M H 2014 Synthesis, insecticidal, and fungicidal screening of some new quinoline derivatives Russ. J. Bioorg. Chem. 40214

9. Całus S, Gondek E, Danel A, Jarosz B, Pokładko M and Kityk A V 2007 Electroluminescence of 6-R-1,3diphenyl-1 $H$-pyrazolo[3,4- $b$ ]quinoline-based organic light-emitting diodes $\left(\mathrm{R}=\mathrm{F}, \mathrm{Br}, \mathrm{Cl}, \mathrm{CH}_{3}, \mathrm{C}_{2} \mathrm{H}_{3}\right.$ and $\left.\mathrm{N}\left(\mathrm{C}_{6} \mathrm{H}_{5}\right)_{2}\right)$ Mater. Lett. 613292

10. Caeiro G, Lopes J M, Magnoux P, Ayrault P and Ribeiro F R 2007 A FT-IR study of deactivation phenomena during methylcyclohexane transformation on 
H-USY zeolites: Nitrogen poisoning, coke formation, and acidity-activity correlations J. Catal. 249234

11. Michael J P 2008 Quinoline, quinazoline and acridone alkaloids Nat. Prod. Rep. 25166

12. Al-Khalil S, Alkofahi A, El-Eisawi D and Al-Shibib A 1998 Transtorine, a New Quinoline Alkaloid from Ephedra transitoria J. Nat. Prod. 61262

13. Wright C W, Addae-Kyereme J, Breen A G, Brown J E, Cox M F, Croft S L, Gökçek Y, Kendrick H, Phillips R M and Pollet P L 2001 Synthesis and evaluation of cryptolepine analogues for their potential as new antimalarial agents J. Med. Chem. 443187

14. Achan J, Talisuna A O, Erhart A, Yeka A, Tibenderana J K, Baliraine F N, Rosenthal P J and D'Alessandro U 2011 Quinine, an old anti-malarial drug in a modern world: Role in the treatment of malaria Malar. J. 10144

15. Fokialakis N, Magiatis P, Chinou I, Mitaku S and Tillequin F 2002 Megistoquinones I and II, two quinoline alkaloids with antibacterial activity from the bark of Sarcomelicope megistophylla Chem. Pharm. Bull. 50 413

16. Ratheesh M, Sindhu G and Helen A 2013 Antiinflammatory effect of quinoline alkaloid skimmianine isolated from Ruta graveolens L Inflamm. Res. 62367

17. (a) Bringmann G, Reichert Y and Kane V V 2004 The total synthesis of streptonigrin and related antitumor antibiotic natural products Tetrahedron 60 3539; (b) Zhu C, Ma X, Hu Y, Guo L, Chen B, Shen K and Xiao Y 2016 Safety and efficacy profile of lenvatinib in cancer therapy: A systematic review and meta-analysis Oncotarget 744545

18. Foley M and Tilley L 1998 Quinoline antimalarials: Mechanisms of action and resistance and prospects for new agents Pharmacol. Ther. 7955

19. (a) ter Kuile F O, Nosten F, Thieren M, Luxemburger C, Edstein M D, Chongsuphajaisiddhi T, Phaipun L, Webster H K and White N J 1992 High-dose mefloquine in the treatment of multidrug-resistant falciparum malaria J. Infect. Dis. 166 1393; (b) Schlagenhauf P 1999 Mefloquine for malaria chemoprophylaxis 19921998: A review J. Travel Med. 6122

20. Kaur K, Jain M, Reddy R P and Jain R 2010 Quinolines and structurally related heterocycles as antimalarials Eur. J. Med. Chem. 453245

21. (a) Wall M E, Wani M C, Cook C E, Palmer K H, McPhail A T and Sim G A 1966 Plant antitumor agents. I. The isolation and structure of camptothecin, a novel alkaloidal leukemia and tumor inhibitor from Camptotheca acuminata J. Am. Chem. Soc. 88 3888; (b) Mukherjee A K, Basu S, Sarkar N and Ghosh A C 2001 Advances in cancer therapy with plant based natural products Curr. Med. Chem. 8 1467; (c) Fuchs C, Mitchell E P and Hoff P M 2006 Irinotecan in the treatment of colorectal cancer Cancer Treat. Rev. 32 491; (d) Garst J 2007 Topotecan: An evolving option in the treatment of relapsed small cell lung cancer Ther. Clin. Risk Manag. 3 1087; (e) Fallahi P, Ferrari S M, Bari F D, Materazzi G, Benvenga S, Miccoli P and Antonelli A 2015 Cabozantinib in thyroid cancer recent patents on Anticancer Drug Discov. 10 259; (f) Vaishampayan U 2013 Cabozantinib as a novel therapy for renal cell carcinoma Curr. Oncol. Rep. 1576
22. Afzal O, Kumar S, Haider M R, Ali M R, Kumar R, Jaggi $M$ and Bawa S 2015 A review on anticancer potential of bioactive heterocycle quinoline Eur. J. Med. Chem. 97871

23. (a) Bisacchi G S 2015 Origins of the quinolone class of antibacterials: An expanded "discovery story" J. Med. Chem. 58 4874; (b) Aubier M, Lode H, GialdroniGrassi G, Huchon G, Hosie J, Legakis N, Regamey C, Segev S, Vester R, Wijnands W J and Tolstuchow N 1996 Sparfloxacin for the treatment of communityacquired pneumonia: A pooled data analysis of two studies J. Antimicrob. Chemother. 3773

24. Zhanel G G, Ennis K, Vercaigne L, Walkty A, Gin A S, Embil J, Smith H and Hoban D J 2002 A critical review of the fluoroquinolones Drugs 6213

25. Kumar S, Bawa S and Gupta H 2009 Biological activities of quinoline derivatives Mini-Rev. Med. Chem. 9 1648

26. (a) Trost B M and Crawley M L 2003 Asymmetric transition-metal-catalyzed allylic alkylations: Applications in total synthesis Chem. Rev. 103 2921; (b) D'Souza D M and Muller T J J 2007 Multi-component syntheses of heterocycles by transition-metal catalysis Chem. Soc. Rev. 361095

27. (a) Bharate J B, Vishwakarma R A and Bharate S B 2015 Metal-free domino one-pot protocols for quinoline synthesis RSC Adv. 5 42020; (b) Kouznetsov V V, Méndez L Y V and Gómez C M M 2005 Recent progress in the synthesis of quinolines Curr. Org. Chem. 9141

28. (a) Kharb R and Kaur H 2013 Therapeutic significance of quinoline derivatives as antimicrobial agents Int. Res. J. Pharm. 4 63; (b) Krishnal S and White N J 1996 Pharmacokinetics of quinine, chloroquine and amodiaquine Clin. Pharmacokinet. 30263

29. Kour P, Kumar A, Sharma R, Chib R, Khan I A and Rai V K 2017 Synthesis of 2-amino-4H-chromen-4ylphosphonates and $\beta$-phosphonomalonates via tandem Knoevenagel Phospha-Michael reaction and antimicrobial evaluation of newly synthesized $\beta$ phosphonomalonates Res. Chem. Intermed. 437319

30. Zhong M, Sun S, Cheng J and Shao Y 2016 Iron-catalyzed cyclization of nitrones with geminalsubstituted vinyl acetates: A direct [4 + 2] assembly strategy leading to 2,4-disubstituted quinolines J. Org. Chem. 8110825

31. Yan R, Liu X, Pan C, Zhou X, Li X, Kang X and Huang G 2013 Aerobic synthesis of substituted quinoline from aldehyde and aniline: Copper-catalyzed intermolecular $\mathrm{C}-\mathrm{H}$ active and C-C formative cyclization Org. Lett. 15 4876

32. Pang X, Wu M, Ni J, Zhang F, Lan J, Chen B and Yan R 2017 Copper-catalyzed tandem aerobic oxidative cyclization for the synthesis of polysubstituted quinolines via $\mathrm{C}\left(\mathrm{sp}^{3}\right) / \mathrm{C}\left(\mathrm{sp}^{2}\right)-\mathrm{H}$ bond functionalization $J$. Org. Chem. 8210110

33. Mondal R R, Khamarui S and Maiti D K 2016 CuBr$\mathrm{ZnI}_{2}$ combo-catalysis for mild $\mathrm{Cu}^{\mathrm{I}}-\mathrm{Cu}^{\mathrm{III}}$ Switching and $\mathrm{sp}^{2} \mathrm{C}-\mathrm{H}$ activated rapid cyclization to quinolines and their sugar-based chiral analogues: A UV-Vis and XPS study ACS Omega 1251

34. Luo X-L, Liu X-X, Pu J-H, Tian W-F, Zhou X-Q, Wei D-D and Huang G-S 2017 Palladium-catalyzed aerobic 
oxidative synthesis of 3-phenylquinoline with azides and aldehydes ChemistrySelect 28658

35. Nikolaev A, Nithiy N and Orellana A 2014 One-step synthesis of quinolines via palladium-catalyzed crosscoupling of cyclopropanols with unprotected orthobromoanilines Synlett 252301

36. Selvakumar K, Lingam K A P, Varma R V L and Vijayabaskar V 2015 Controlled and efficient synthesis of quinoline derivatives from Morita-BaylisHillman adducts by palladium-catalyzed heck reaction and cyclization Synlett 26646

37. Gao G-L, Niu Y-N, Yan Z-Y, Wang H-L, Wang G-W, Shaukat A and Liang Y-M 2010 Unexpected domino reaction via $\mathrm{Pd}$-catalyzed sonogashira coupling of benzimidoyl chlorides with 1,6-enynes and cyclization to synthesize quinoline derivatives J. Org. Chem. 75 1305

38. Liu B, Gao H, Yu Y, Wu W and Jiang H 2013 Palladiumcatalyzed intermolecular aerobic oxidative cyclization of 2-ethynylanilines with isocyanides: Regioselective synthesis of 4-halo-2-aminoquinolines J. Org. Chem. 7810319

39. Tan Z, Jiang $H$ and Zhang M 2016 Rutheniumcatalyzed dehydrogenative $\beta$-benzylation of $1,2,3$, 4-tetrahydroquinolines with aryl aldehydes: Access to functionalized quinolines Org. Lett. 183174

40. Hu L, Gui W, Liu Z and Jiang B 2014 Synthesis of 3aryl-2-aminoquinolines: Palladium catalyzed cascade reactions of gem-dibromovinylanilines with tert-butyl isocyanide and arylboronic acids $R S C A d v .438258$

41. Patil S S, Patil S V and Bobade V D 2011 Synthesis of aminoindolizine and quinoline derivatives via $\mathrm{Fe}(\mathrm{acac})_{3} / \mathrm{TBAOH}$-catalyzed sequential crosscoupling-cycloisomerization reactions Synlett 162379

42. Mohammadpoor-Baltork I, Tangestaninejad S, Moghadam M, Mirkhani V, Anvar S and Mirjafari A 2010 Microwave-promoted alkynylation-cyclization of 2-aminoaryl ketones: a green strategy for the synthesis of 2,4-disubstituted quinolines Synlett 20 3104

43. Huma HZ S, Halder R, Kalra S S, Das J and Iqbal J 2002 $\mathrm{Cu}(\mathrm{I})$-catalyzed three component coupling protocol for the synthesis of quinoline derivatives Tetrahedron Lett. 436485

44. Huang H, Jiang H, Chen K and Liu H 2009 A Simple and convenient copper-catalyzed tandem synthesis of quinoline-2-carboxylates at room temperature $\mathrm{J}$. Org. Chem. 745476

45. Zeing Z, Deng G and Liang Y 2016 Synthesis of quinolines through copper-catalyzed intermolecular cyclization reaction from anilines and terminal acetylene esters RSC Adv. 6103478

46. Liu P, Li Y, Wang H, Wang Z and Hu X 2012 Synthesis of substituted quinolines by iron-catalyzed oxidative coupling reactions Tetrahedron Lett. 536654

47. Xu X, Zhang X, Liu W, Zhao Q, Wang Z, Yu L and Shi F 2015 Synthesis of 2-substituted quinolines from alcohols Tetrahedron Lett. 563790

48. Maizuru N, Inami T, Kurahashi $\mathrm{T}$ and Matsubara S 2011 Nickel-catalyzed cycloadditions of benzoxazinones with alkynes: Synthesis of quinolines and quinolones Chem. Lett. 40375
49. Korivi R P and Cheng C-H 2006 Nickel-catalyzed cyclization of 2-iodoanilines with aroylalkynes: An efficient route for quinoline derivatives J. Org. Chem. 71 7079

50. Sarode P B, Bahekar S P and Chandak H S 2016 $\mathrm{Zn}(\mathrm{OTf})_{2}$-mediated C-H activation: An expeditious and solvent-free synthesis of aryl/alkyl substituted quinolines Tetrahedron Lett. 575753

51. Zheng J, Li Z, Huang L, Wu W, Li J and Jiang H 2016 Palladium-catalyzed intermolecular aerobic annulation of $o$-alkenylanilines and alkynes for quinoline synthesis Org. Lett. 183514

52. Song G, Gong X and Li X 2011 Synthesis of quinolines

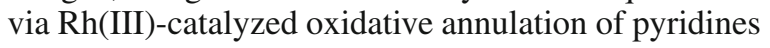
J. Org. Chem. 767583

53. Kumar G S, Kumar P and Kapur M 2017 Traceless directing-group strategy in the ru-catalyzed, formal [3 +3 ] annulation of anilines with allyl alcohols: a onepot, domino approach for the synthesis of quinolines Org. Lett. 192494

54. Xu J, Sun J, Zhao J, Huang B, Li X and Sun Y 2017 Palladium-catalyzed synthesis of quinolines from allyl alcohols and anilines RSC Adv. 736242

55. Mastalir M, Glatz M, Pittenauer E, Allmaier G and Kirchner K 2016 Sustainable synthesis of quinolines and pyrimidines catalyzed by manganese PNP pincer complexes J. Am. Chem. Soc. 13815343

56. Wang R, Fan H, Zhao W and Li F 2016 Acceptorless dehydrogenative cyclization of $o$-aminobenzyl alcohols with ketones to quinolines in water catalyzed by watersoluble metal-ligand bifunctional catalyst $\left[\mathrm{Cp}^{*}(6,6\right.$ '$(\mathrm{OH})_{2}$ bpy $\left.)\left(\mathrm{H}_{2} \mathrm{O}\right)\right][\mathrm{OTf}]_{2}$ Org. Lett. 183558

57. Chen S-J, Lu G-P and Cai C 2015 Synthesis of quinolines from allylic alcohols via iridium-catalyzed tandem isomerization/cyclization combined with potassium hydroxide Synthesis $\mathbf{4 7} 976$

58. Motokura K, Mizugaki T, Ebitani K and Kaneda K 2004 Multifunctional catalysis of a Ruthenium-grafted hydrotalcite: One-pot synthesis of quinolines from 2aminobenzyl alcohol and various carbonyl compounds via aerobic oxidation and Aldol reaction Tetrahedron Lett. 456029

59. Cho C S, Kim B T, Kim T-J and Shim S C 2001 Ruthenium-catalyzed oxidative cyclisation of 2-aminobenzyl alcohol with ketones: Modified Friedlaender quinoline synthesis Chem. Commun. 242576

60. Li H-J, Wang C-C, Zhu S, Dai C-Y and Wu Y-C 2015 Ruthenium(II)-catalyzed hydrogen transfer/annulation cascade processes between alcohols and 2-nitrobenzaldehydes Adv. Synth. Catal. 357 583

61. Anand N, Chanda T, Koley S, Chowdhury S and Singh M S $2015 \mathrm{CuSO}_{4}$-D-glucose an inexpensive and eco-efficient catalytic system: Direct access to diverse quinolines through modified Friedländer approach involving $\mathrm{S}_{N}$ Ar/reduction/annulation cascade in onepot RSC Adv. 57654

62. Soleimani E, Khodaei M M, Batooie N and Samadi S 2010 An efficient approach to quinolines via Friedländer synthesis catalyzed by cuprous triflate Chem. Pharm. Bull. 58212 
63. Cho C S, Ren W X and Yoon N S 2009 A recyclable copper catalysis in modified Friedländer quinoline synthesis J. Mol. Catal. A 299117

64. Mierde H V, Ledoux N, Allaert B, Voort P V D, Drozdzak R, Vos D D and Verpoort F 2007 Improved ruthenium catalysts for the modified Friedlaender quinoline synthesis New J. Chem. 311572

65. Cho C S and Ren W X 2007 A recyclable palladiumcatalyzed modified Friedlander quinoline synthesis $J$. Organometal. Chem. 6924182

66. Cho C S, Ren W X and Shim S C 2006 A copper(II)catalyzed protocol for modified Friedlander quinoline synthesis Tetrahedron Lett. 476781

67. De S K and Gibbs R A 2005 A mild and efficient onestep synthesis of quinolines Tetrahedron Lett. 461647

68. Cho C S, Ren W X and Shim S C 2005 Synthesis of quinolines via $\mathrm{Pd} / \mathrm{C}$-catalyzed cyclization of 2aminobenzyl alcohol with ketones Bull. Korean Chem. 261286

69. Cho C S, Seok H J and Shim S C 2005 A Rhodiumcatalyzed route for oxidative coupling and cyclization of 2-aminobenzyl alcohol with ketones leading to quinolines J. Heterocycl. Chem. 421219

70. Taguchi K, Sakaguchi S and Ishii Y 2005 Synthesis of quinolines from amino alcohol and ketones catalyzed by $[\mathrm{IrCl}(\mathrm{cod})]_{2}$ or $\mathrm{IrCl}_{3}$ under solvent-free conditions Tetrahedron Lett. 464539

71. McNaughton B R and Miller B L 2003 A mild and efficient one-step synthesis of quinolines Org. Lett. 5 4257

72. Monrad R N and Madsen R 2011 Ruthenium-catalyzed synthesis of 2- and 3-substituted quinolines from anilines and 1,3-diols Org. Biomol. Chem. 9610

73. Jin J, Guidi S, Abada Z, Amara Z, Selva M, George M W and Pdiakoff M 2017 Continuous Niobium phosphate catalyzed Skraup reaction for quinoline synthesis from solketal Green Chem. 192439

74. Horn J, Marsden S P, Nelson A, House D and Weingarten G G 2008 Convergent, regiospecific synthesis of quinolines from $o$-aminophenylboronates Org. Lett. 104117

75. Khan S and Volla C M R 2017 Cu-catalyzed cascade cyclization of isothiocyanates, alkynes and diaryliodonium salts: Access to diversely functionalized quinolines Chem. Eur. J. 2312462

76. Tiwari D K, Phanindrudu M, Wakade S B, Nanubolu J B and Tiwari D K $2017 \alpha, \beta$-Functionalization of saturated ketones with anthranils via $\mathrm{Cu}$-catalyzed sequential dehydrogenation/aza-Michael addition/annulation cascade reactions in one-pot Chem. Commun. 53 5302

77. Xia X-F, Zhang G-W, Wang D and Zhu S-L 2017 Visible-light induced and oxygen-promoted oxidative cyclization of aromatic enamines for the synthesis of quinolines derivatives J. Org. Chem. 828455

78. Chi Y, Yan H, Zhang W-X and Xi Z 2017 Synthesis of quinoline derivatives via $\mathrm{Cu}$-catalyzed cascade annulation of heterocumulenes, alkynes, and diaryliodonium salts Org. Lett. 192694

79. Carrel-Menoyo A, Ortiz-de-Elguea V, Martinez-Nunes M, Sotomayor N and Lete E 2017 Palladium-catalyzed dehydrogenative coupling: An efficient synthetic strategy for the construction of the quinoline core Mar. Drugs 15276

80. Zhang X, Liu W, Sun R, Xu X, Wang Z and Yan Y 2016 Silver-catalyzed three-component approach to quinolines starting from anilines, aldehydes, and alcohols Synlett 271563

81. Yao R, Rong G, Yan B, Qiu L and Xu X 2016 Dual-functionalization of alkynes via copper-catalyzed carbene/alkyne metathesis: A direct access to the 4carboxyl quinolines ACS Catal. 61024

82. Chen W, Ding Q, Nie Z and Peng Y 2016 Synthesis of 2-trifluoromethylquinolines via coppermediated intramolecular oxidative cyclization of N-(2alkenylaryl) enamines $R S C A d v .648767$

83. Xu X, Liu W, Wang Z, Feng Y, Yan Y and Zhang X 2016 Silver-catalyzed one-step synthesis of multiply substituted quinolines Tetrahedron Lett. 57226

84. Yang X, Li L, Li Y and Zhang Y 2016 Visiblelight-induced photocatalytic aerobic oxidative $\mathrm{Csp}^{3}-\mathrm{H}$ functionalization of glycine derivatives: Synthesis of substituted quinolines J. Org. Chem. 8112433

85. Neuhaus J D, Morrow S M, Brunavs $M$ and Wills $M$ C 2016 Diversely substituted quinolines via rhodiumcatalyzed alkyne hydroacylation Org. Lett. 181562

86. Iosub A V and Stahl S S 2015 Catalytic aerobic dehydrogenation of nitrogen heterocycles using heterogeneous cobalt oxide supported on nitrogen-doped carbon Org. Lett. 174404

87. Kong L, Zhou Y, Huang H, Yang Y, Liu Y and Li Y 2015 Copper-catalyzed synthesis of substituted quinolines via C-N coupling/condensation from ortho-acylanilines and alkenyl iodides J. Org. Chem. 801275

88. Jiang B, Hu L and Gui W 2014 Facile synthesis of 2-amino-3-bromoquinolines by palladiumcatalyzed isocyanide insertion and cyclization of gemdibromovinylanilines $R S C A d v \mathbf{4} 13850$

89. Senadi G C, Hu W-P, Garkhedkar A M, Boominathan S S K and Wang J-J 2015 Palladium(II)-catalyzed regioselective synthesis of 3,4-disubstituted quinolines and 2,3,5-trisubstituted pyrroles from alkenes via antiMarkovnikov selectivity Chem. Commun. 5113795

90. Zhang Y, Wang M, Li P and Wang L 2012 Ironpromoted tandem reaction of anilines with styrene oxides via $\mathrm{C}-\mathrm{C}$ cleavage for the synthesis of quinolines Org. Lett. 142206

91. Toh K K, Sanjaya S, Sahnoun S, Chong S Y and Chiba S 2012 Copper-catalyzed aerobic intramolecular carboand amino-oxygenation of alkynes for synthesis of azaheterocycles Org. Lett. 142290

92. Patil N T, Raut V S, Shinde V S, Gayatri G and Shastry G N 2012 Gold(I)-catalyzed unprecedented rearrangement reaction between 2-aminobenzaldehydes with propargyl amines: An expedient route to 3aminoquinolines Chem. Eur. J. 185530

93. Sakai N, Tamura K, Shimamura K, Ikeda R and Konakahara T 2012 Copper-catalyzed [5+1] annulation of 2-ethynylanilines with an $\mathrm{N}, \mathrm{O}$-acetal leading to construction of quinoline derivatives Org. Lett. 14836

94. Wang Z, Li S, Yu B, Wu H, Wang Y and Sun X 2012 $\mathrm{FeCl}_{3} \cdot 6 \mathrm{H}_{2} \mathrm{O}-\mathrm{Catalyzed} \mathrm{intramolecular}$ allylic amination: Synthesis of substituted dihydroquinolines and quinolines J. Org. Chem. 778615 
95. Xing R-G, Li Y-N, Liu Q, Han Y-F, Wei X, Li J and Zhou B 2011 Selective reduction of nitroarenes by a hantzsch 1,4-dihydropyridine: A facile and efficient approach to substituted quinolines Synthesis 132066

96. Richter H and Mancheno O G 2011 TEMPO oxoammonium salt-mediated dehydrogenative povarov/oxidation tandem reaction of N-alkyl anilines Org. Lett. 136066

97. Patil N T and Raut V S 2010 Cooperative catalysis with metal and secondary amine: Synthesis of 2-substituted quinolines via addition/cycloisomerization cascade $J$. Org. Chem. 756961

98. Huo Z, Gridnev I D and Yamamoto Y 2010 A method for the synthesis of substituted quinolines via electrophilic cyclization of 1-azido-2-(2-propynyl)benzene J. Org. Chem. 751266

99. Sarma R and Prajapati D 2008 Ionic liquid — an efficient recyclable system for the synthesis of 2,4-disubstituted quinolines via Meyer-Schuster rearrangement Synlett 193001

100. Zhang Z, Tan J and Wang Z 2008 A facile synthesis of 2-methylquinolines via Pd-catalyzed Aza-Wacker oxidative cyclization Org. Lett. 10173

101. Gabriele B, Mancuso R, Salerno G, Ruffolo G and Plastina P 2007 Novel and convenient synthesis of substituted quinolines by copper- or palladium-catalyzed cyclodehydration of 1-(2-aminoaryl)-2-yn-1-ols J. Org. Chem. 726873

102. Liu X-Y, Ding P, Huang J-S and Che C-M 2007 Synthesis of substituted 1,2-dihydroquinolines and quinolines from aromatic amines and alkynes by gold(I)catalyzed tandem hydroamination-hydroarylation under microwave-assisted conditions Org. Lett. 92645

103. Yadav J S, Reddy B V S, Sreedhar P, Rao R S and Nagaiah K 2004 Silver phosphotungstate: A novel and recyclable heteropoly acid for Friedländer quinoline synthesis Synthesis $\mathbf{1 4} 2381$

104. O'Dell D K and Nicholas K M 2003 synthesis of 3 -substituted quinolines via transition-metal-catalyzed reductive cyclization of o-nitro Baylis-Hillman acetates J. Org. Chem. 686427

105. Hatano M and Mikami K 2003 Highly Enantioselective quinoline synthesis via ene-type cyclization of 1,7enynes catalyzed by a cationic BINAP-palladium(II) complex J. Am. Chem. Soc. 1254704

106. Abbiati G, Arcadi A, Canevari V, Capezzuto L and Rossi E 2005 Palladium-assisted multicomponent synthesis of 2-aryl-4-aminoquinolines and 2-aryl-4amino[1,8] napthyridines J. Org. Chem. 706454

107. Anguille S, Brunet J J, Chu N C, Diallo O, Pages C and Vincendeau S 2006 Platinum-catalyzed formation of quinolines from anilines. Aliphatic $\alpha-\mathrm{C}-\mathrm{H}$ activation of alkylamines and aromatic ortho-C-H activation of anilines Organometallics 252943

108. Lee H and Yi C S 2016 Catalytic synthesis of substituted indoles and quinolines from the dehydrative C-H coupling of arylamines with 1,2 and 1,3-diols Organometallics 351973

109. Zhang X, Liu B, Shu X, Gao Y, Lv H and Zhu J 2012 Silver mediated C-H activation: Oxidative coupling/cyclization of $\mathrm{N}$-arylimines and alkynes for the synthesis of quinolines J. Org. Chem. 77501

110. Mohsenimehr M, Mamaghani M, Shirini F, Sheykhan M, Abbapour S and Sabet L S 2015 One-pot synthesis of novel pyrimido[4,5-b]quinolines and pyrido[2,3-d:6,5$\mathrm{d} /$ ddipyrimidine using encapsulated- $\gamma-\mathrm{Fe}_{2} \mathrm{O}_{3}$ nanoparticles J. Chem. Sci. 1271895

111. Das S, Maiti D and Sarkar S D 2018 Synthesis of polysubstituted quinolines from $\alpha$-2-aminoaryl alcohols via Nickel-catalyzed dehydrogenative coupling $J$. Org. Chem. 832309

112. Xu X, Yang Y, Zhang X and Yi W 2018 Direct synthesis of quinolines via co(III)-catalyzed and DMSO-involved C-H activation/cyclization of anilines with alkynes Org. Lett. 20566

113. Tan D W, Li H X, Zhu D L, Li H Y, Young D J, Yao J L and Lang J P 2018 Ligand- controlled copper (I)-catalyzed cross-coupling of secondary and primary alcohols to $\alpha$-alkylated Ketones, Pyridines and Quinolines Org. Lett. 20608

114. Jadhav S D and Singh A 2017 Oxidative annulations involving DMSO and formamide: $\mathrm{K}_{2} \mathrm{~S}_{2} \mathrm{O}_{8}$ mediated synthesis of Quinolines and Pyrimidines Org. Lett. 19 5673

115. Parua S, Sikari R, Sinha S, Das S, Chakraborty G and Paul N D 2018 A Nickel catalyzed acceptorless dehydrogenative approach to quinolines Org. Biomol. Chem. 16274

116. Xu X, Yang Y, Chen X, Zhang X and Yi W 2017 One pot synthesis of Quinolines via Co(III)-catalyzed C$\mathrm{H}$ activation/carbonylation/cyclization of anilines $\mathrm{Org}$. Biomol. Chem. 159061

117. Ni J, Jiang Y, An Z and Yan R 2018 Cleavage of C-C bonds for the synthesis of C_2-substituted quinolines and indoles by catalyst-controlled tandem annulation of 2-vinylanilines and alkynoates Org. Lett. 20 1534

118. Jiang K-M, Kang J-A, Jin Y and Lin J 2018 Synthesis of substituted 4-hydroxyalkyl-quinoline derivatives by a three-component reaction using $\mathrm{CuCl} / \mathrm{AuCl}$ as sequential catalysts Org. Chem. Front. 5434 